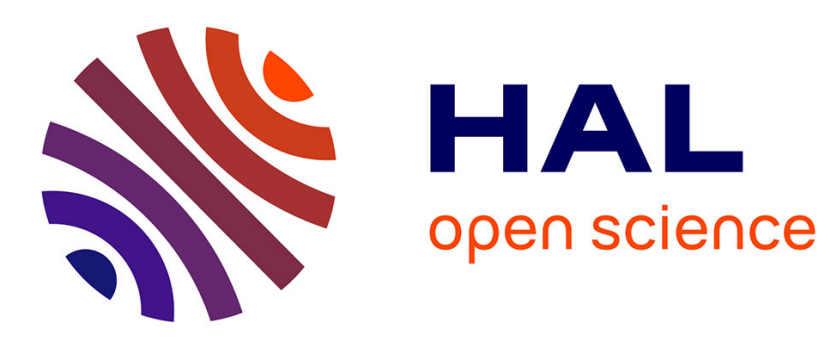

\title{
The loss of Latin OV: steps towards an analysis
}

Lieven Danckaert

\section{To cite this version:}

Lieven Danckaert. The loss of Latin OV: steps towards an analysis. Aboh, Enoch; Haeberli, Eric; Puskás, Genoveva; Schönenberger, Manuela. Elements of comparative syntax: theory and description, De Gruyter Mouton, pp.401-446, 2017, Studies in Generative Grammar 127, 978-1-5015-0403-7. 10.1515/9781501504037-015 . halshs-01657596

\section{HAL Id: halshs-01657596 \\ https://shs.hal.science/halshs-01657596}

Submitted on 6 Dec 2017

HAL is a multi-disciplinary open access archive for the deposit and dissemination of scientific research documents, whether they are published or not. The documents may come from teaching and research institutions in France or abroad, or from public or private research centers.
L'archive ouverte pluridisciplinaire HAL, est destinée au dépôt et à la diffusion de documents scientifiques de niveau recherche, publiés ou non, émanant des établissements d'enseignement et de recherche français ou étrangers, des laboratoires publics ou privés. 
The loss of Latin OV: steps towards an analysis

Lieven Danckaert (CNRS, Université de Lille 3)

1. Introduction: diagnosing object placement in Latin

This paper is concerned with the alternation between the word orders OV and VO in Latin. ${ }^{1}$ As is well known, in the Romance languages only the latter variant survives, but at this point little is known about why the OV-order was lost. As a starting point I will take the discussion of object placement in Latin offered in Danckaert (2017: chapter 3). As shown there, direct object noun phrases can appear in various positions in the Latin clause. ${ }^{2}$ One can make a basic distinction between VP-internal and VP-external objects. Importantly, whether or not a given object appears VP-internally can only be diagnosed in clauses with an auxiliary and a non-finite verb, i.e. monoclausal environments in which the auxiliary lexicalizes some projection in the T-domain, and where the (non-finite) lexical verb occupies a lower position, plausibly one inside the (articulated) VP-layer. ${ }^{3}$ In contrast, object placement in clauses with a single verb form are always (multiple ways) ambiguous. Consider why this is so.

Following among others Embick (2000) I will assume that the phrase structure of the minimal pair in (1) is not fundamentally different, in that both tokens involve a monoclausal domain with an equal amount of functional structure. In the a-example we see an OV-clause with the synthetic verb form obtinuit '(he) obtained', whereas the quasi-synonymous example in (1b) contains an analytic form of the deponent predicate adipiscor 'obtain', consisting of a (transitive) past participle and a finite BE-auxiliary:

\begin{tabular}{|c|}
\hline $\begin{array}{l}\text { imperi-um } \\
\text { supreme authoritv-ACC }\end{array}$ \\
\hline
\end{tabular}

\footnotetext{
${ }^{1}$ It is my great pleasure to dedicate this paper to my supervisor, mentor, occasional co-author and good friend Liliane Haegeman, whose work on word order in Flemish/Dutch has always been a major source of inspiration for my own work on Latin. Non-standard abbreviations used are the following: FOFC $=$ Final-Over-Final Constraint; HNPS = Heavy Noun Phrase Shift; ObjP = Object Phrase; PLD = Primary Linguistic Data; SubjP: Subject Phrase. In the glosses, abbrevations not mentioned in the Leipzig Glossing Rules are COMP for "comparative", PLPRF for "pluperfect" and PRT for "particle". In references to Latin examples, the same abbreviations are used as in the Oxford Latin Dictionary. The research reported on in this paper was funded by a postdoctoral grant of the Research Foundation - Flanders, grant nr. FWO13/PDO/024.

${ }^{2}$ In this paper I will not be concerned with direct objects that are unambiguously leftperipheral (on which, see Danckaert 2012), focusing only on those objects that appear in the TP or VP-layer.

${ }^{3}$ Throughout this paper I will informally use the term "verb phrase" (VP) as shorthand for a more complex structure involving more than one projection (see for instance the trees in (2) and (3)). Similarly, the labels "TP" and "CP" also refer to more elaborate structures (the inflectional layer and articulated left periphery respectively).
} 

b. imperi-um adept-us est
supreme.authority-ACC obtained-NOM be.PRS.3SG
'He obtained the empire.' (Tac. Ann. 2.42.3)

A first approximation of a structural representation of (1a) is given in (2a): I will further refine this analysis in section 3. The structure in (2a) features an articulated verb phrase consisting of three layers, with an a-categorial root at the bottom of the extended projection, a verbalizing head $v$ right on top of that, and thirdly a Voice head which determines whether a given clause is transitive or not. In the case of transitive clauses, an agentive, external argument is present in SpecVoiceP. As can be observed, I take it that synthetic lexical verbs like obtinuit evacuate the verb phrase through repeated application of head movement, to end up in $\mathrm{T}^{\circ}$. The direct object imperium sits in its base position, which $\mathrm{I}$ take to be the complement position of the lexical root. Note that for reasons of space, here and in the remainder of this paper I do not represent bar levels of projections which do not have an overtly filled specifier: for instance, in (2a) (in which overt terminals are marked in boldface) VoiceP is represented as a leftward complement of $\mathrm{T}^{\circ}$, and this pair of nodes is immediately dominated by TP: ${ }^{4}$

(2) a.

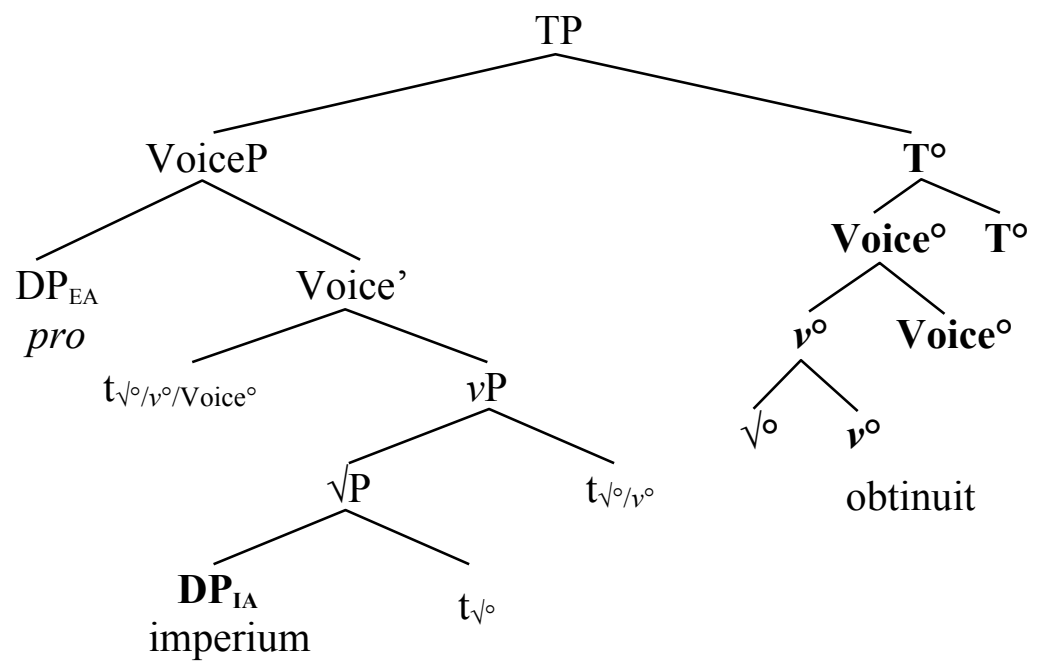

In contrast, in a clause with an analytic deponent verb, the T-node is lexicalized by a base generated auxiliary, and the lexical verb appears much lower in the structure. Again following Danckaert (2017), I assume that in the case of non-finite verbs the root head moves to $v$ (but not to Voice). The structure of a clause like (1b) can thus be detailed as in (2b):

\footnotetext{
${ }^{4}$ For the sake of simplicity, here and elsewhere in this paper I represent complement-head sequences as base-generated as such rather than being derived through movement (which would be in line with the antisymmetric programme laid out in Kayne (1994)). Nothing crucially hinges on this.
} 
b.

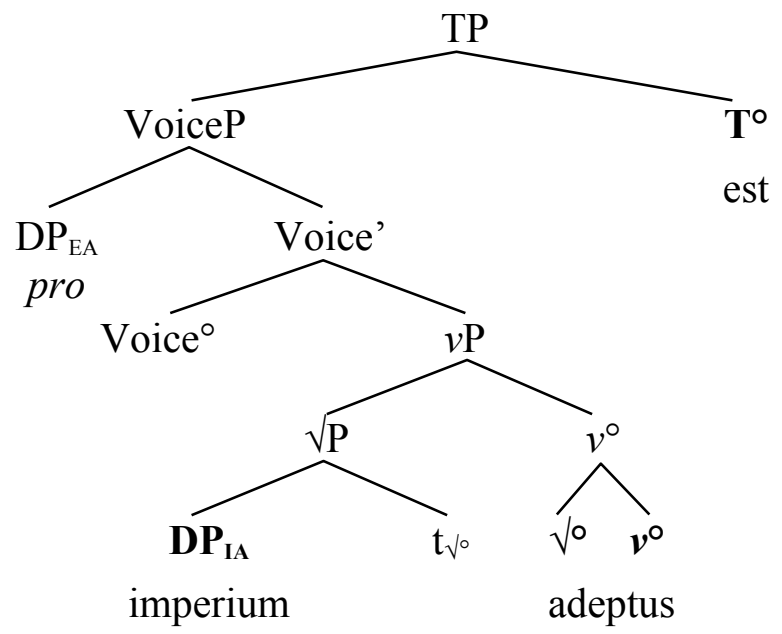

In other words, the synthetic/analytic alternation illustrated in (1) is not associated with a difference qua phrase structure, but rather, it involves two different lexicalization patterns of the same syntactic structure.

Consider now why monoclausal domains with more than one verb form provide us with more accurate information about object placement than clauses with a single verb. Imagine for instance that the structure of (1a) did not involve a head-final $v \mathrm{P}$ (as in (2a)), but rather a head-initial one, as in (3a), where $\mathrm{T}^{\circ}$ is shorthand for an internally complex verbal head (cf. $(2 a))$ :

(3) a.

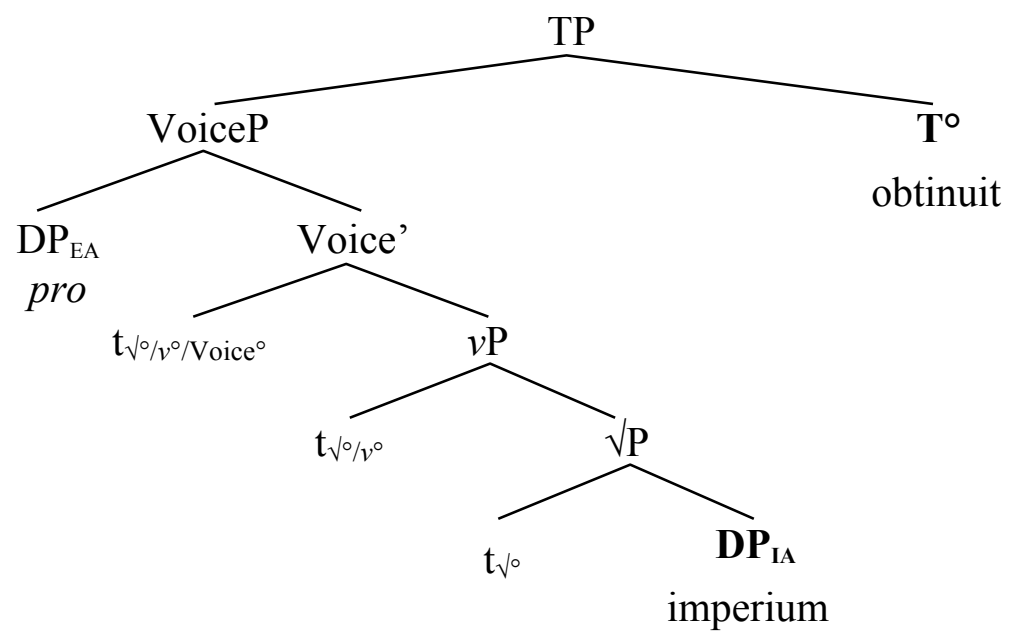

Importantly, although there is a clear structural difference between (2a) and (3a) (headfinal $v \mathrm{P}$ vs. head-initial $v \mathrm{P}$ ), this difference is not reflected in the linear string. However, in the case of clauses with an analytic deponent verb, changing the headedness of $v \mathrm{P}$ does in fact translate into a different surface word order. More specifically, a structure like (3b) yields the order VOAux rather than OVAux (2b): 
b.

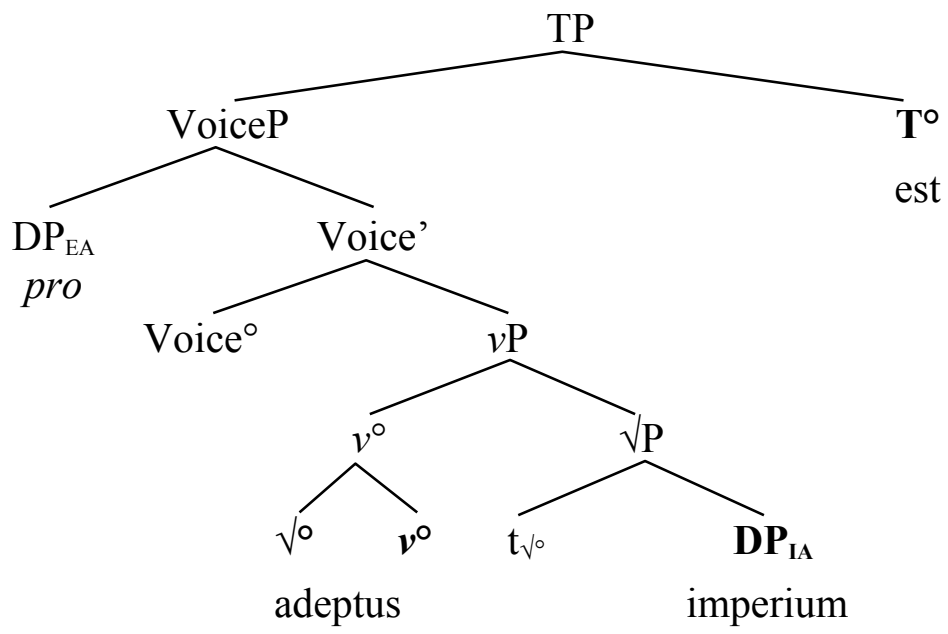

In other words, in the absence of a second verb form, it is impossible to tell apart VPinternal OV from VP-internal VO. Therefore, I will only take into account data from clauses with a direct object, an auxiliary and a non-finite verb. Crucially, it is important to make sure that a given selection of clauses with an auxiliary only contains monoclausal domains which only differ in the number of overtly lexicalized verb forms they feature, and not in the number of possible object positions. As argued at length in Danckaert (2017), two such environments are available in Latin, namely (i) clauses with an analytic deponent verb of the type exemplified in (1b), and (ii) clauses with a modal verb (possum 'be able' or debeo 'have to') (on the monoclausal status of the latter environment, see Danckaert 2017: 140-173).

Again as a first approximation, I will consider clauses featuring the orders OVAux and AuxOV to exemplify VP-internal OV, whereas the orders VOAux and AuxVO can be taken to involve VP-internal VO. I will refer to the grammar that generates VP-internal OV as the OV grammar, and to the one that gives rise to VP-internal VO as the VO grammar. I will adopt the "competing grammars" approach to language variation and change (Kroch 1989, 1994), which assumes that the language learner can acquire full competence in two or more grammars whose output is perhaps functionally, but not truth-conditionally distinct. As will be discussed in more detail in section 4, each competing grammar is associated with a different probability of usage. In the case at hand, we can safely assume that both the OV and the VO grammar were available to speakers of Latin throughout the entire period under investigation (viz. $200 \mathrm{BC}-600 \mathrm{AD}$ ).

Importantly, in clauses with more than one verb form we can also distinguish two types of VP-external objects. In VAuxO-clauses, we see a type of VP-external VO which I will call "extraposition". On the other hand, in clauses featuring the order OAuxV, the object can be said to have undergone leftward movement to a position outside the verb phrase, yielding a non-local type of OV which I will refer to as "object shift". Note that in many cases, two of the word order patterns that I classified earlier as VP-internal are actually structurally ambiguous, in that they could also involve a VP-external object. More particularly, OVAuxclauses are ambiguous between an [[OV]Aux] (VP-internal OV) and an [O [[ $\left.\left.t_{O} \mathrm{~V}\right] \mathrm{Aux}\right]$ (VPexternal OV) parse, and AuxVO-clauses can either be analysed as [Aux[VO]] (VP-internal $\mathrm{VO}$ ), or as [Aux[ $\left.\left.\left.\mathrm{V} \mathrm{t}_{\mathrm{O}}\right]\right] \mathrm{O}\right]$ (VP-external VO). I will come back to this particular issue in section 5 .

In the following section, I will give a descriptive overview of the most important developments concerning object placement in the history of Latin, starting with VP-internal objects. 
2. Object placement in the history of Latin: a descriptive overview

\subsection{VP-internal OV and VO}

The data to be presented in this and the following subsection are drawn from a corpus study of 38 Latin text samples (3.604.912 words) dating from ca. $200 \mathrm{BC}$ until $600 \mathrm{AD}{ }^{5}$ From this corpus, I collected a sample of 6.365 clauses with an auxiliary (BE, possum or debeo), a transitive lexical verb, and an overt, non-left-peripheral direct object. I only included direct objects realized as a noun phrase or as a demonstrative pronoun (and thus excluding all personal pronouns functioning as a direct object, as well as all clausal objects).

In Graph 1, I have plotted the diachronic development of VP-internal VO. More specifically, what is shown is the average frequency (in percentages) of the word order patterns AuxVO and VOAux (as compared to the combined frequencies of the orders AuxOV and OVAux). In order to make sure that the estimated values are as accurate as possible, I excluded all data points which do not contain at least 20 clauses with an auxiliary and a VPinternal object. The full dataset as well as the R-code used to produce all graphs, tables and statistical tests are available at the following URL: https://opendata.uit.no/dataset.xhtml?persistentId=doi:10.18710/VWDJ1Y.

\footnotetext{
${ }^{5}$ This is the same sample as the one used in Danckaert (2017), modulo the fact that the Vulgate was left out of account, as object placement in this text is quite different than in any other Late Latin text. I hope to address the topic of object placement in Biblical Latin in future work. Also, note that in Danckaert (2017) no pronominal objects (i.e. not even demonstratives) were taken into account.
} 


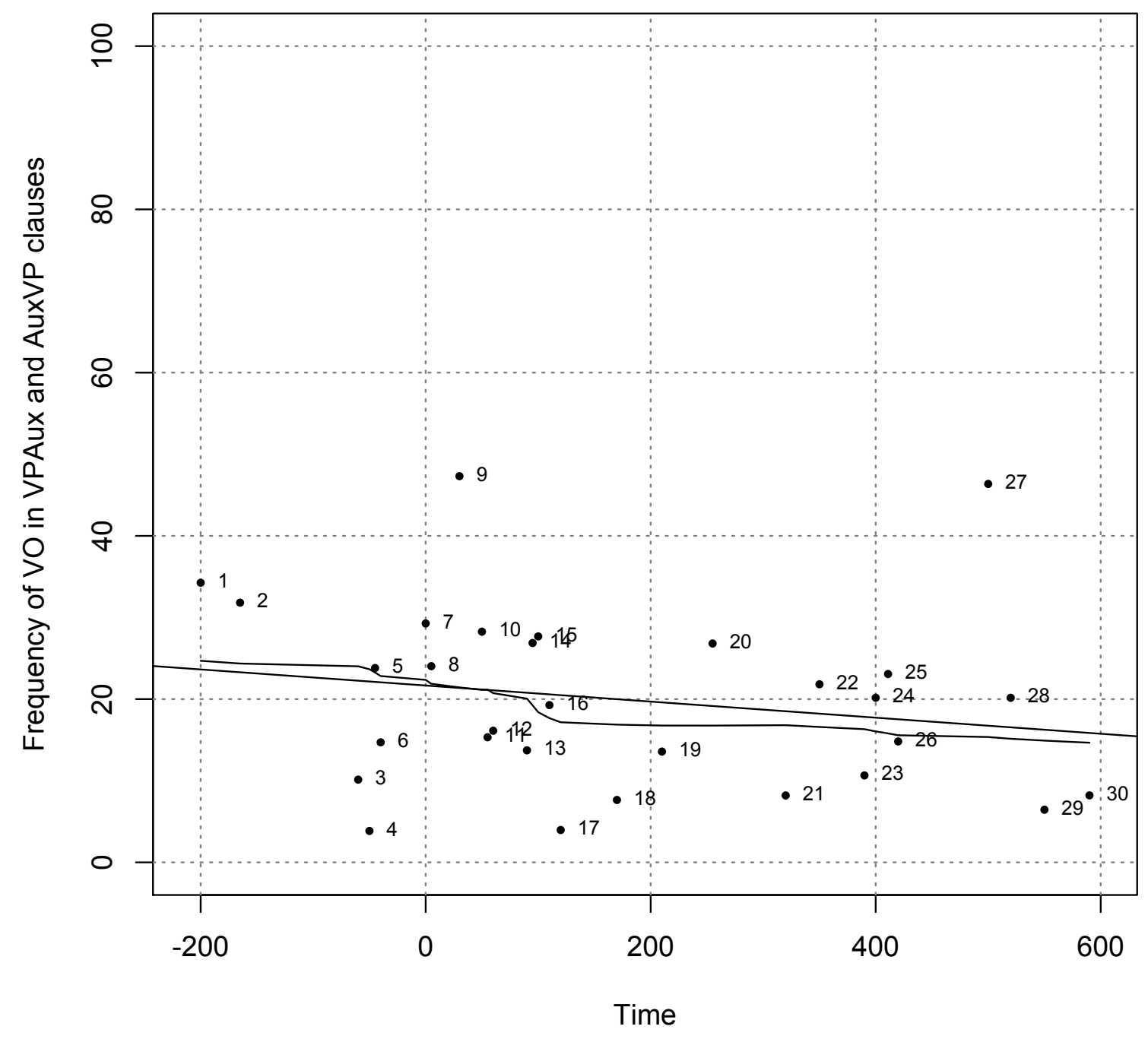

Graph 1: Frequency (in \%) of the order VO in clauses with an auxiliary (BE or modal), unambiguously VP-external objects excluded, ca. 200 BC -600 AD. Case labels: 1= Plautus, $2=$ Terence, $3=$ Cicero, $4=$ Caesar, $5=$ Varro, $6=$ Sallust, $7=$ Vitruvius, $8=$ Livy, $9=$ Celsus, $10=$ Seneca, $11=$ Columella, $12=$ Petronius, $13=$ Frontinus, $14=$ Quintilian, $15=$ Pliny the Younger, 16= Tacitus, $17=$ Suetonius, $18=$ Gaius, $19=$ Tertullian, $20=$ Cyprian, $21=$ Historia Augusta, 22= Palladius, 23= Jerome, 24= Augustine, 25= Gesta Conlationis Carthaginiensis, 26= Vegetius, 27 $=$ Pompeius Maurus, 28 $=$ Caesarius of Arles, 29= Iordanes, 30= Gregory.

Let me briefly comment upon what can be observed in this data set. First of all, recall that some of the tokens in this sample of VP-internal objects are actually structurally ambiguous: more particularly, some of the AuxVO-examples might well involve object extraposition, but as we will see below, there are reasons to assume that the amount of noise that this complicating factor adds to the data remains fairly constant over time. Second, throughout the entire period we see a fair amount of synchronic variation (spread above and below the regression lines), whose exact nature is at this point not well understood. In all likelihood, at a synchronic level the distribution of object noun phrases is to a large extent sensitive to the referentiality/information status of the object, as well as to for instance its syntactic category (full noun phrase vs. demonstrative pronoun), and related to this, its prosodic weight and internal complexity. Third, as suggested by both the straight and the smoothed regression lines, there does not seem to be any major diachronic development with 
respect to the frequency of the order VO, which remains constant at about $20 \%$. If anything, the data reveal a minor decrease of the head-initial order. ${ }^{6}$

However, when we have a closer look at the data, it appears that this diachronic stability is only apparent. In particular, as shown in Graph 2, the development of the VO pattern is very different in VPAux and in AuxVP-clauses. The most important observation is that in Late Latin, the order VO is highly dispreferred in VPAux-clauses, whereas it readily occurs in Late Latin AuxVP-clauses: ${ }^{7}$

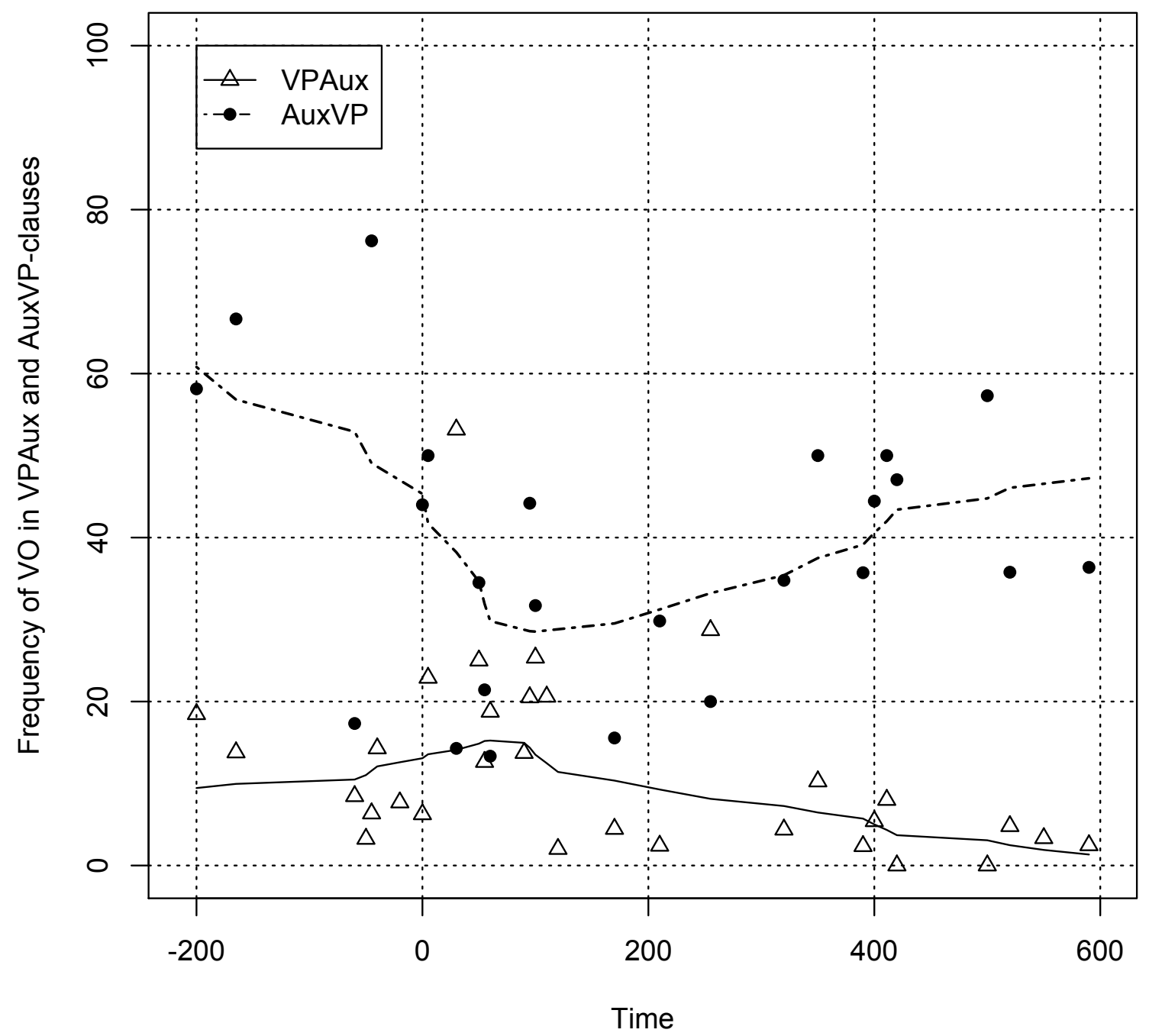

Graph 2: Frequency (in \%) of the order VO in clauses with an auxiliary (BE or modal), VP-external objects excluded, ca. 200 BC - 600 AD. VPAux and AuxVP-clauses compared.

\footnotetext{
${ }^{6}$ It is unlikely that this diachronic trend is significant: if we split up the data set in Graph 1 into two subsets, an earlier one with all the data points from before $200 \mathrm{AD}$, and a later one with the samples from after that date, and if we compare the average rates of VO in these two periods, it turns out that a slight difference in absolute terms $(21.00 \%$ vs. $18.36 \%)$ is not statistically significant (independent samples t-test, $\mathrm{p}=.5324$ ).

${ }^{7}$ In Graph 2 I only included authors/texts for which my corpus contains a sufficient amount of clauses featuring an auxiliary, a transitive $\mathrm{V}$ and a (pro)nominal direct object in both AuxVP and VPAux-clauses (viz. a minimum of 12 tokens per type of clause).
} 
As can be observed, in the case of VPAux-clauses the VO-order is the minority variant in all but one of the subsamples (viz. Celsus at $30 \mathrm{AD}$ ), and the only period in which the order VOAux is more or less productive is around the $1^{\text {st }}$ century AD. Importantly, the relevant pattern is strongly dispreferred by all authors after Cyprian (ca. $250 \mathrm{AD}$ ). The development of the VO pattern in AuxVP-clauses is more difficult to evaluate (partly because I only have information from four samples dating from before $0 \mathrm{AD}$ ). On the one hand, we observe very high values for three (very) early authors (viz. Plautus at $200 \mathrm{BC}$, Terence at $165 \mathrm{BC}$ and Varro at $45 \mathrm{BC}$ ). On the other hand, if we were to abstract away from these data points, in the remainder of the texts there seems to be some upward trend. I leave it for future research to investigate whether taking into account a number of synchronic variables (see my earlier remarks) can help us to assess with more confidence if it is indeed the case that the factor Time is a good predictor to model the OV/VO alternation in AuxVP-clauses.

In any event, it seems clear that there is a marked contrast between the left-hand half of Graph 2 and the right-hand one. The most plausible way to interpret these facts would be to assume that the observed contrast is a reflex of a major shift from one grammatical system to another. In what follows, I will refer to these two systems as Grammar A and Grammar B, which I take to be in competition with one another in the same way as the OV and the VO grammar. As will be elaborated on in section 3, we can assume that Grammar A was more prevalent in the early stages of the period documented in my corpus, and that Grammar B is more strongly represented in later times. The transition from A to B has no doubt been a gradual process, but given the fairly sharp contrast between the first and the last four centuries in Graph 2, it seems to be the case that the spread of Grammar B (and the concomitant demise of Grammar A) accelerated quite fast at some point before $200 \mathrm{AD}$. One can hypothesize that Grammar B was available (but perhaps used at very low frequencies) from the earliest texts onwards, but as ever, it is impossible to tell when exactly this new grammar was first actuated.

\subsection{VP-external OV and VO}

I now turn to two types of VP-external object placement, namely object extraposition (which results in a linear VO-sequence) and object shift (a type of non-local OV). As mentioned, a given OV or VO-sequence is often structurally ambiguous between a VPinternal and a VP-external parse, which is why I will pay special attention to the way in which object extraposition and object shift can be distinguished from structures involving a VPinternal object.

\subsubsection{Object extraposition}

I will start by discussing object extraposition, which for now I will informally define as the occurrence of a direct object DP in a clause-final position, without this DP being located inside the VP, a characterization that I will further refine in section 5.1.2. Roughly speaking, there are two families of analyses of XP extraposition, one involving right adjunction to TP (or to some other maximal projection in the articulated middle field, or even in the left periphery), and one involving leftward movement of the "extraposed" constituent, followed by remnant movement of some portion of the extended verb phrase (as in Kayne 1994). Here I will not take a stance as to which analysis is on the right track.

As mentioned, in Latin object extraposition can only be observed in VPAux-clauses: whenever we find the order VAuxO, we can be sure that the object has been extraposed. In contrast, in AuxVP-clauses it is much more difficult to diagnose extraposition, as many AuxVO patterns are (at least) two-ways ambiguous: I will return to this point in section 5. 
Importantly for the study of the OV/VO alternation, in VAuxO-clauses it is impossible to determine the headedness of $v \mathrm{P}$, and as a result this type of clause does not inform the language learner about the genuine competition between the OV and the VO grammar (as defined above). As shown in (4) (a representation of (5a), in which for the sake of simplicity a rightward movement analysis of extraposition is assumed), it is not clear whether the base position of the direct object reum is to the left or to the right of the lexical verb:

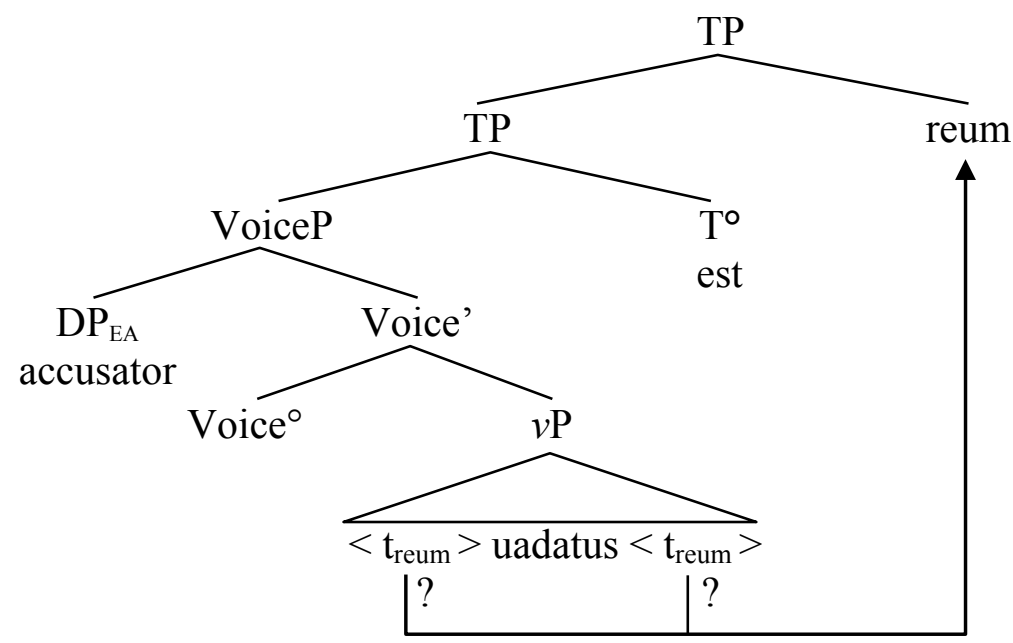

Given our current state of knowledge, there is close to nothing we know about the synchronic determinants of object extraposition. For one thing, it is not clear whether an extraposed object DP is systematically associated with a particular information status (old or new information, afterthought,...). In any event, it does not seem to be the case that only prosodically heavy constituents can be extraposed (still assuming an informal characterization of this phenomenon). Consider for instance the two examples in (5). Although longer DPs, such as the (bracketed) modified direct object in (5b), are perhaps more likely to be extraposed, a short bare noun such as reum '(the) accused' can also occur to the right of a VAux-sequence (5a):

$\begin{array}{lllll}\text { a. } & \text { Tot } & \text { uad-ibus } & \text { accusator uadat-us } \\ & \text { so.many } & \text { guarantees-ABL } & \text { prosecutor.NOM admitted.to.bail-NOM.M.SG }\end{array}$ est re-um.

be.PRS.3SG accused-ACC

'With so many guarantees the prosecutor admitted the accused to bail.' (Liv. 3.13.8)

b. Complex-us es [funest-um illud animal embraced-NOM.M.SG be.PRS.2SG deadly-ACC this.ACC.N.SG animal.ACC ex nefari-is stupr-is, ex civil-i cruor-e, out.of horrible-ABL sexual.misconduct-ABL out.of civil-ABL blood-ABL ex omn-i sceler-um inportunitat-e concret-um]. out.of all-ABL crimes-GEN relentlessness-ABL composed-ACC 'You embraced this deadly monster, composed of horrible misconduct, civil bloodshed, and all sorts of perverse crimes.' (Cic. Pis. 21)

I will return to this last point in section 5.1 .2 below, where I will suggest that the two examples in (5) represent two fundamentally different types of object extraposition, which are presumably associated with different semantic and/or pragmatic properties. 
Let us now have a look at the diachronic development of object extraposition in Latin. Graph 3 shows the relative frequency of this pattern over time, compared to the (combined) incidence of the orders OVAux and VOAux (all averages calculated on the basis of samples consisting of at least 21 clauses):

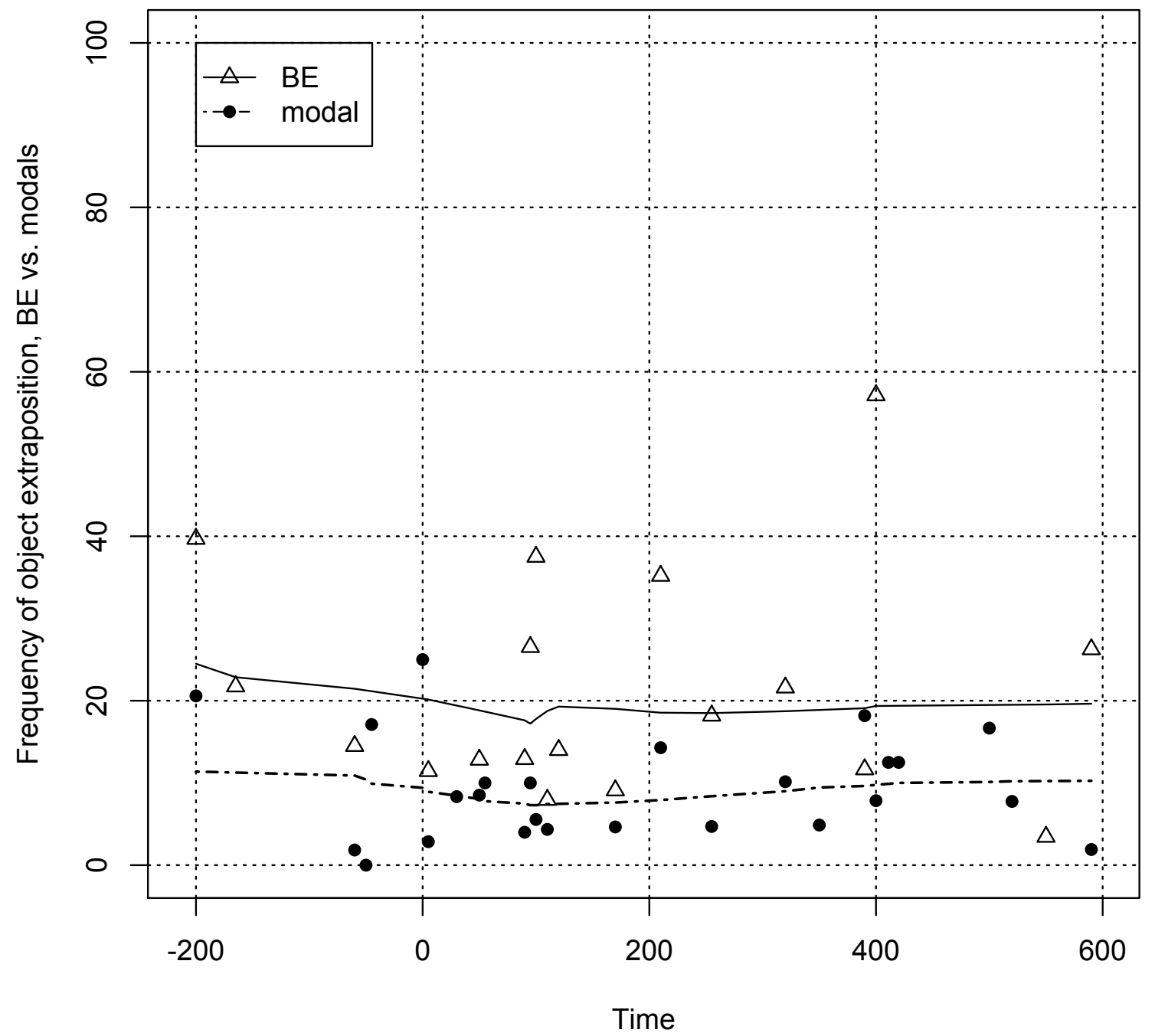

Graph 3: Frequency (in \%) of the order VAuxO, ca. 200 BC - 600 AD.

Clauses with a BE-auxiliary and a modal compared.

As can be observed, I have plotted the data for clauses with a BE-auxiliary and with a modal separately, as the two conditions do not exactly pattern alike, the rate of object extraposition being on average about twice as high in clauses with a transitive deponent predicate. In any event, there does not seem to be any major diachronic development with respect to the availability of noun phrase extraposition, in either condition. When we compare the incidence of extraposition in the earlier period (all texts until $200 \mathrm{AD}$ ) with the corresponding data for the later period, we see that the phenomenon is slightly more frequent in the second period (a mean frequency $12.87 \%$ in the earlier period, compared to $15.88 \%$ in the later one), but as can be expected, this difference is not statistically significant (independent samples t-test, $\mathrm{p}=.3916){ }^{8}$ The two boxplots in Graph 4 visualize this

\footnotetext{
${ }^{8}$ Note that I am lumping together the data for the two auxiliary types.
} 
comparison perhaps more clearly, where the horizontal lines inside the boxes represent the median (rather than the mean) of each group:

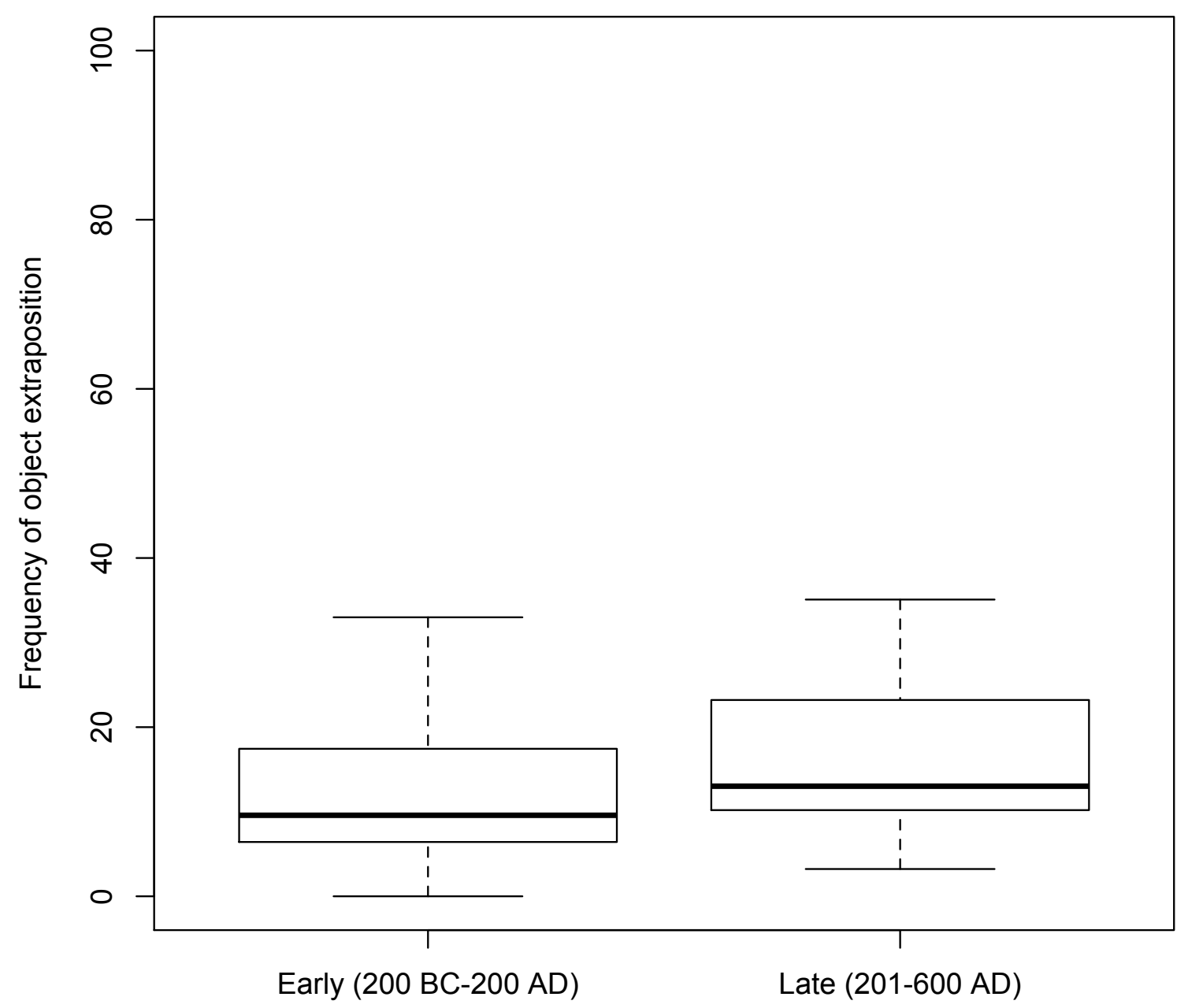

Graph 4: Frequency (in \%) of the order VAuxO, early and late period compared.

On the basis of the data reviewed in the past section, we can conclude that it is unlikely that the phenomenon of object extraposition is in any crucial way related to the eventual decline of the OV-order (for a similar observation on extraposition in the history of Yiddish, see Santorini (1993)). I will now proceed to show that the facts pertaining to the diachrony of object shift are perhaps more interesting.

\subsubsection{Object shift}

The second pattern of VP-external object placement is a type of non-local OV, which can be diagnosed unambiguously whenever we find the order OAuxV. I will refer to this pattern as "object shift", without prejudging anything about the discourse interpretation of the phenomenon (I could alternatively have called it "scrambling"), and without implying that the analysis of the Latin data is to be assimilated to comparable middle field phenomena in present day Germanic languages. An example is given in (6), and a (simplified) structure of this word order pattern involving left adjunction to TP is given in (7): ${ }^{9}$

${ }^{9}$ Alternatively, one could of course assume a structure with movement to the specifier of a dedicated functional projection. In the present context nothing hinges on this. For discussion 
(6) Denique ex bellic-a uictori-a non fere quemquam then from military-ABL victory-ABL not almost anyone.ACC est inuidi-a ciu-ium consecut-a. be.PRS.3SG jealousy-NOM citizens-GEN followed-NOM.F.SG

'Almost nobody has incurred the hatred of fellow citizens after a victory in war.' (Cic. Sest. 51)

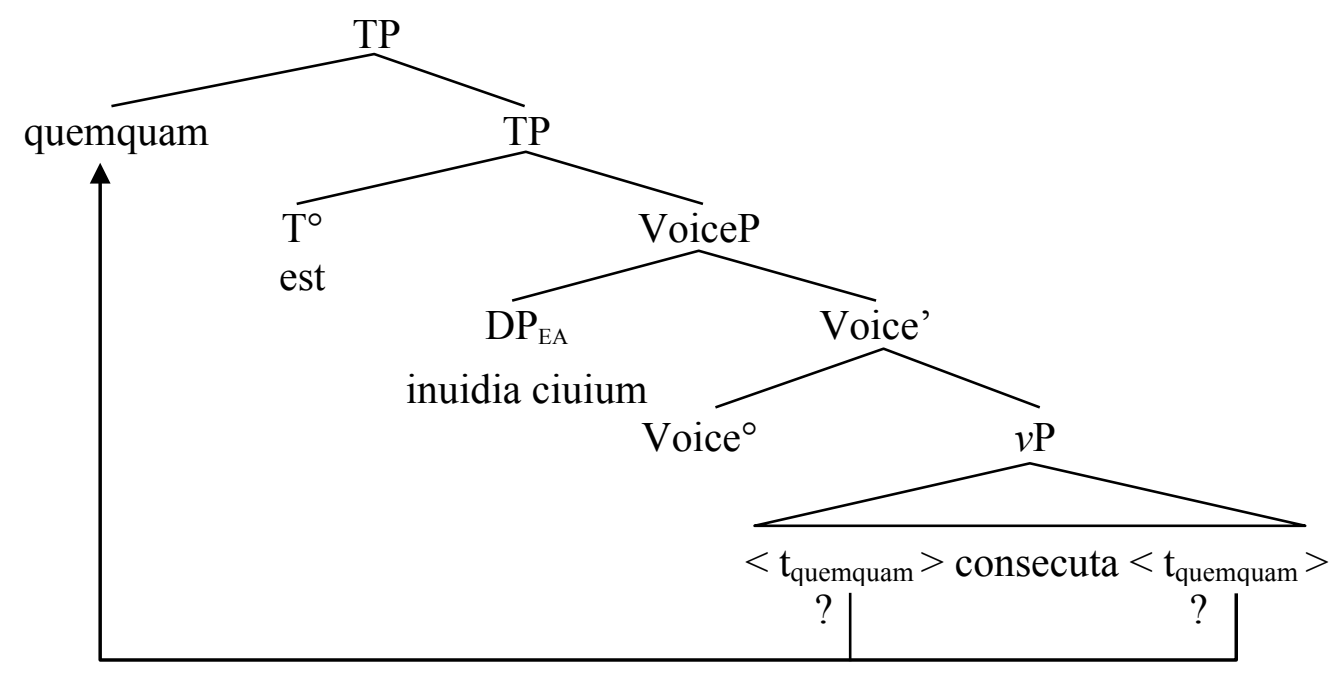

Before I turn to the diachronic development of this word order pattern, a few comments are in order concerning Late Latin BE-auxiliaries. As pointed out in Danckaert (2016, 2017: chapter 6), in Late Latin periphrastic verb forms consisting of a form of esse 'be' and a (passive or deponent) past participle show a very strong - and unexpected - preference for appearing in the head-final order PaPa-Aux. As a result, data about object placement in AuxVP-clauses with an analytic deponent verb in Late Latin are scarce, and therefore difficult to interpret. More particularly, for the entire last 400 years in the corpus, I only found 74 AuxVP-clauses with a nominal direct object in clauses with a BE-auxiliary, compared to 289 tokens in the first four centuries. In contrast, in clauses with a modal verb, no such "small sample size issue" arises at all:

Table 1: Object placement in AuxVP-clauses with a BE-auxiliary and a modal (absolute frequencies).

\begin{tabular}{|l|c|c|c|c|}
\cline { 2 - 5 } \multicolumn{1}{c|}{} & \multicolumn{2}{c|}{ Early (200 BC-200 AD) } & \multicolumn{2}{c|}{ Late (201 - 600 AD) } \\
\multicolumn{1}{c|}{} & BE & modal & BE & modal \\
\hline AuxVO & 28 & 185 & 11 & 251 \\
\hline AuxOV & 24 & 412 & 5 & 349 \\
\hline OAuxV & 237 & 309 & 58 & 487 \\
\hline Totals: & 289 & 906 & 74 & 1087 \\
\hline
\end{tabular}

For this reason, I will illustrate the diachronic development of object shift on the basis of data from clauses with a modal verb. The basic picture is given in Graph 5, which shows the relative frequency of the order OAuxV (as compared to the combined frequencies of the

of an additional type of object movement which targets a position below T (and I which I will refer to as short-distance object scrambling), see sections 5.1.1 and 5.1.2.3. 
orders AuxOV and AuxVO) in 23 data points in my corpus with a least 20 clauses with a modal verb, a transitive $\mathrm{V}$ and a (pro)nominal direct object:

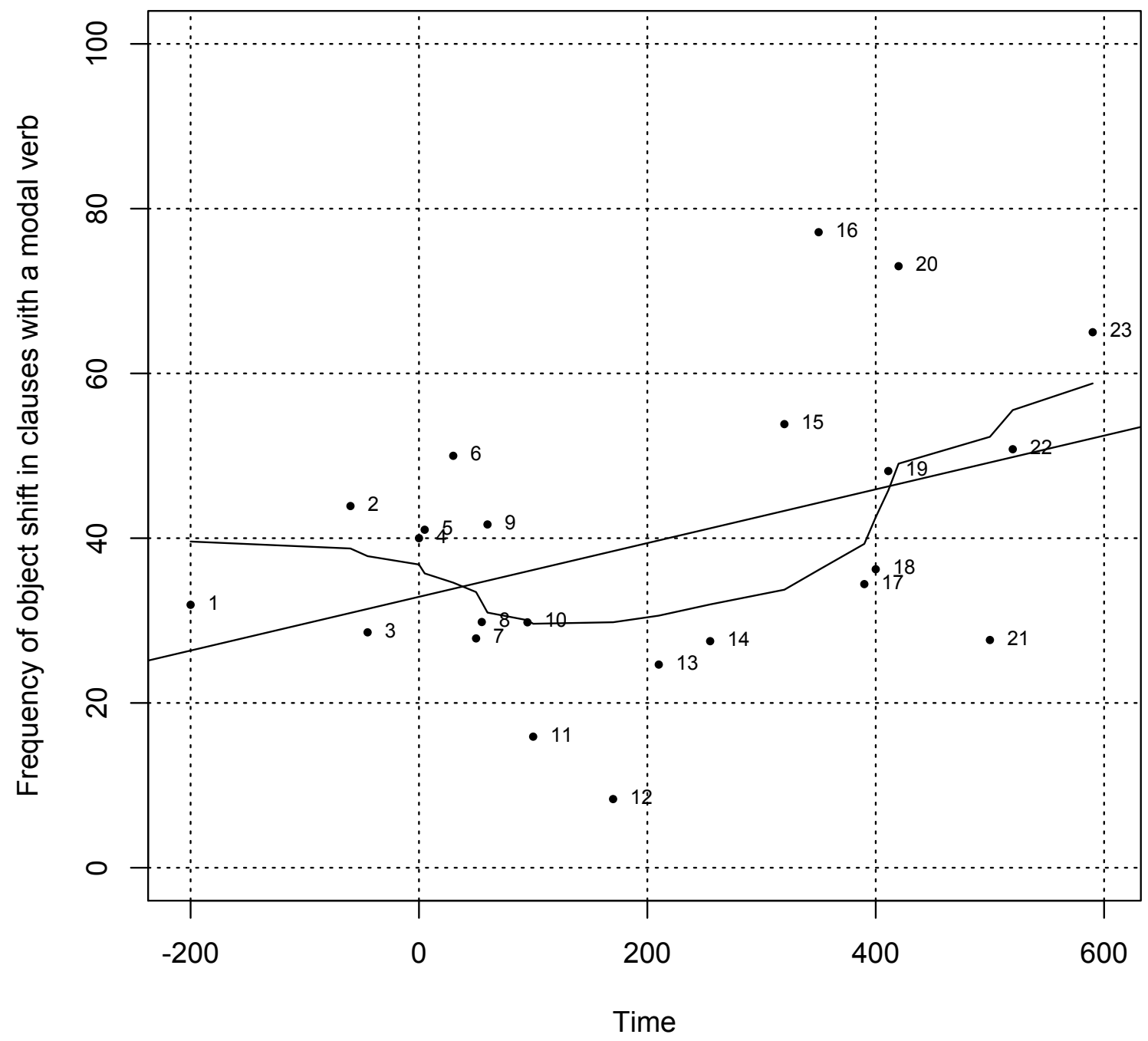

Graph 5: Frequency (in \%) of the order OAuxV in clauses with a modal verb, ca. $200 \mathrm{BC}-$ 600 AD. Case labels: $1=$ Plautus, $2=$ Cicero, $3=$ Varro, $4=$ Vitruvius, $5=$ Livy, $6=$ Celsus, $7=$ Seneca, $8=$ Columella, $9=$ Petronius, $10=$ Quintilian, $11=$ Pliny the Younger, $12=$ Gaius, $13=$ Tertullian, 14= Cyprian, 15= Historia Augusta, 16= Palladius, 17= Jerome, 18= Augustine, 19= Gesta Conlationis Carthaginiensis, 20= Vegetius, 21= Pompeius Maurus, 22 $=$ Caesarius of Arles, 23= Gregory.

As suggested by the discrepancy between the trajectories of the smoothed and the straight regression lines, the diachronic trend in this data set is partly obscured by a great amount of synchronic variation, but it seems clear enough that the incidence of object shift does not remain constant over time. Rather, object shift appears to be more frequent in the later centuries.

This is confirmed when we adopt a cruder time measure and simply compare the average rate of object shift in the earlier period with the corresponding value for the later period: 


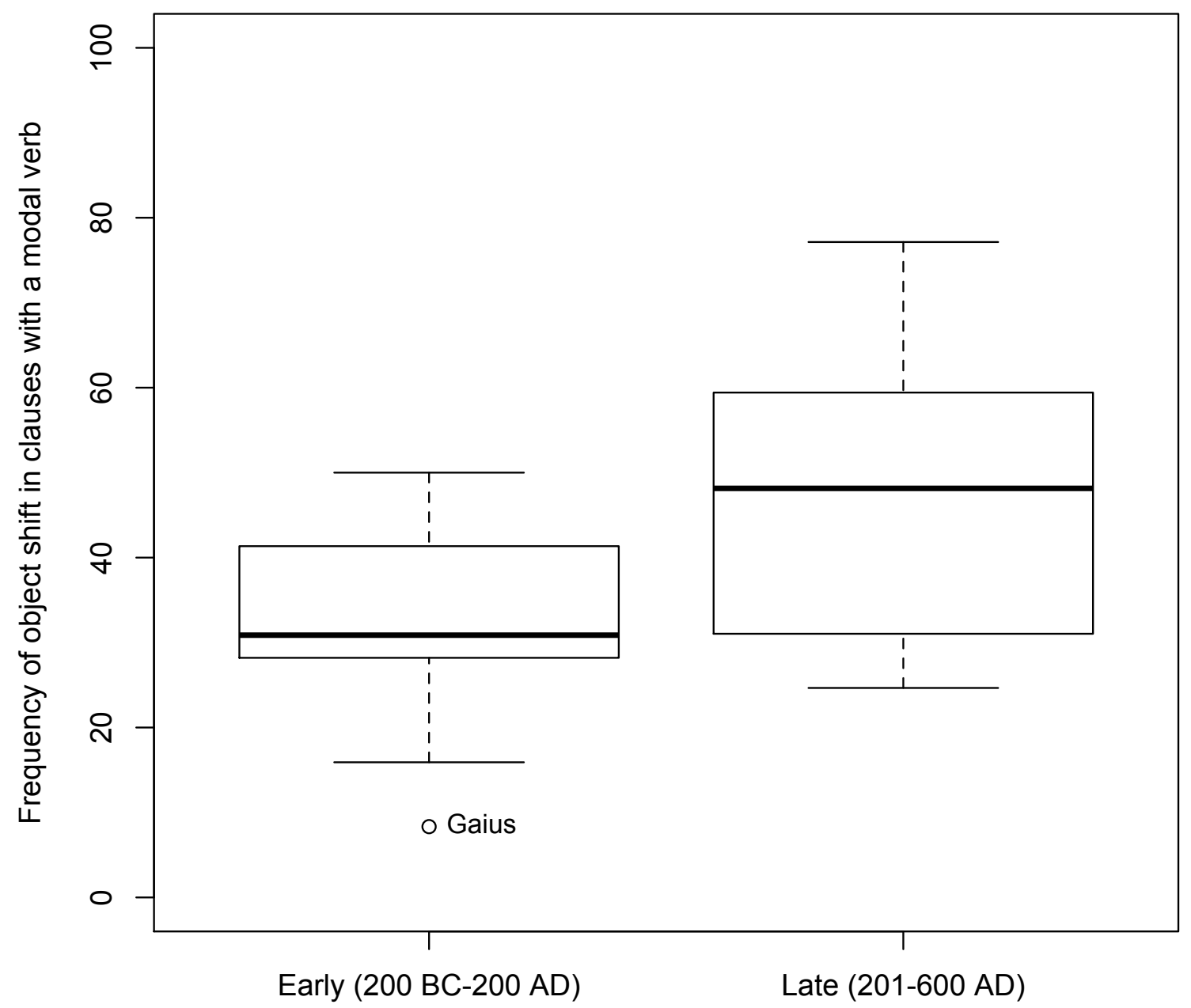

Graph 6: Frequency (in \%) of the order OAuxV, early and late period compared.

In the first period, the mean rate of application of object shift is $32.40 \%$, compared to $47.13 \%$ in the later one. This difference can be shown to be statistically significant (independent samples t-test, $\mathrm{p}=.03977$ ).

\subsection{Interim summary}

To sum up this descriptive section, we can say that despite the fact that the overall rate of $\mathrm{VO}$ does not increase during the lifespan of the Latin language, there is good evidence that syntax of object placement does not remain constant throughout the 800 years studied. First, in Late Latin the availability of the order VO clearly becomes sensitive to the headedness of the T-node (or whatever functional projection BE-auxiliaries and modal verbs are located in) (cf. Graph 2). Second, we have also seen that there is a change concerning one particular pattern of VP-external object placement, viz. the OAuxV-order which I referred to as "object shift" (Graphs 5 and 6). On the other hand, the rate of object extraposition cannot be shown to change over time (Graphs 3 and 4).

In the remainder of this paper, I would like to explore the idea that the object shift data - despite leading to higher frequencies of surface OV - can shed light on the eventual loss of VP-internal OV: both phenomena can be thought to follow from a more general reorganization of the structure of the Latin clause. In section 3, I will start by elaborating on the properties of Grammar A and Grammar B, and I will show how these two systems differ with respect to possible patterns of object placement. Next, in section 4 I will introduce 
Yang's $(2000,2002)$ model of language change, which makes crucial reference to the notion of competing grammars mentioned earlier. Finally, in sections 5 and 6 I will apply this model to the diachrony of Latin object placement. I will argue that the conditions under which the OV grammar can be cued are very different in Classical and in Late Latin, and that it is ultimately the shift from Grammar A to Grammar B that caused the VO grammar to prevail. I will also propose that the increased frequency of object shift is to be understood as a side effect of this same change in clause structure.

\section{Latin clause structure in diachrony}

In this section I provide an overview of the main properties of Grammar A and Grammar B, i.e. the older and the more innovative grammatical system that I distinguished on the basis of visual inspection of Graph 2. The discussion is entirely based on Danckaert (2017), to which the reader is referred for further details and references.

\subsection{Grammar A}

The core idea is that the parametric difference between Grammar A and Grammar B is related to the way in which the EPP requirement is satisfied. As a starting point I will adopt the idea that there is a functional head in the articulated T-field which bears an EPP-feature. Simply put, the syntax has to insert an element endowed with $\varphi$-features in that particular locus of the clause. Following among others Alexiadou \& Anagnostopoulou (1998), Biberauer (2003) and Biberauer \& Roberts (2005) I will assume that there are multiple syntactic mechanisms available to satisfy a clause's EPP requirement. In a nutshell, the relevant requirement can either be satisfied by means of V-movement, DP-movement, or expletive insertion. In addition, moving verbs or DPs can also pied-pipe other phrasal material, leading to a derivation in which an entire VP is displaced, much along the lines of Haegeman (2000). ${ }^{10}$ Finally, EPP-checking through V-movement (without pied-piping) goes hand in hand with optional (discourse-driven) subject movement. The reader is referred to the references mentioned as well as to Danckaert (2017) for further discussion.

Against the backdrop of this parametric system, it was proposed in Danckaert (2017) that Grammar A employs the mechanism of VP movement to satisfy the clause's EPP requirement. To be more precise, what is probed for is the hierarchically highest nominal argument in the extended verb phrase, and when undergoing movement this element piedpipes the entire verb phrase. The basic structure of such a derivation looks like in (8), which is a more accurate representation of a Classical Latin INFL-final clause than the one given earlier in (2a). In this structure, EPP-driven VP movement effectively derives the VPAux order characteristic of especially Early and Classical Latin.

\footnotetext{
${ }^{10}$ For a very comparable proposal on Latin, see also Mackenzie \& van der Wurff (2012).
} 
(8)

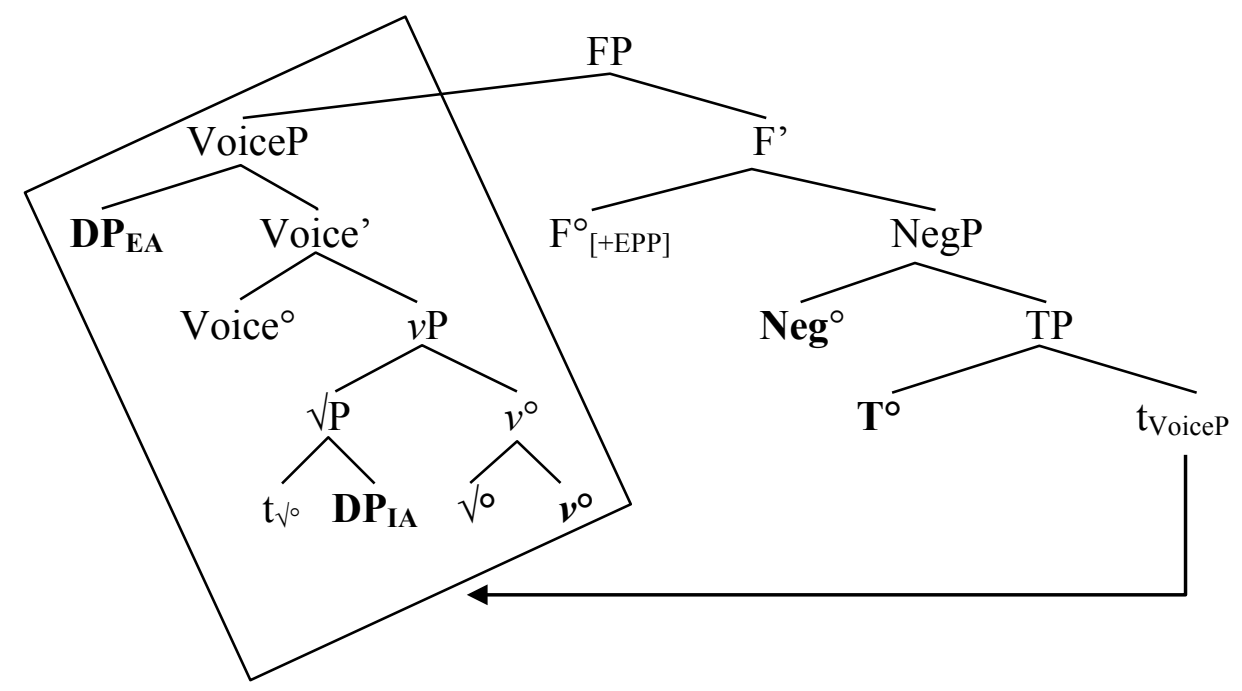

As can be observed, I am assuming that an EPP feature is located in a projection that I labelled "FP", without further committing myself to the exact nature of this functional head. In any event, one has to assume that the relevant instance of VP movement is not strictly local, as there clearly is functional structure present between the launching and the landing site of the moved VP (at least T and Neg, witness the availability of VP-Neg-Aux orders). Note also that under this analysis, subject DPs do not undergo A-movement, but remain in their base position (unless of course they are A'-moved at a later stage of the derivation, cf. section 5.1.1). Importantly, to the best of my knowledge there is no positive evidence for there being more than one non-left-peripheral position for (preverbal) subjects in Grammar A. ${ }^{11}$ In other words, in this grammar all unambiguously non-left-peripheral preverbal subjects should be located inside the verb phrase. I will come back to this in section 3.3.

One important consequence of this analysis is that the structure derived through EPPdriven movement is not subject to the Final-Over-Final-Constraint (FOFC) as defined by Biberauer, Holmberg \& Roberts (2014), which rules out all (and only) structures in which a head-final projection dominates one or more head-initial projections (in the same extended projection). Now recall that up until the beginning of the second century AD, VO-orders in VPAux-clauses are attested at fairly high frequencies in Latin (cf. Graph 2), which suggests that the VOAux-orders thus created do not involve a VP which is dominated by (the highest node of) TP. Rather, if we assume that VPAux-orders in Grammar A do indeed involve nonlocal displacement, it follows that the external syntax of the VP has no influence on the availability of OV and VO-orders.

Before moving on to discussing the properties of Grammar B, let me briefly comment on early occurrences of the order Aux-V. Given the by assumption universal character of the EPP requirement, and given the lack of alternative mechanisms to satisfy the EPP in the context of Grammar A, it would follow that in this grammar, the verb phrase is moved past $\mathrm{T}$ in every single clause, yielding only $\mathrm{V}(\mathrm{P})$-Aux orders. This conclusion is potentially at odds with the well known fact that AuxVP-clauses are attested from the earliest texts onwards. However, as argued in Danckaert (2017: 238-240), there is evidence that at least some of these early AuxVP-orders are in fact derived by means of VP movement and subsequent auxiliary fronting. Such a structure would look like (9):

${ }^{11}$ One way to further test whether this is indeed the case would be to look at placement of subjects with respect to adverbs (in VOAux-clauses, generated by Grammar A). Note that there is good evidence that in Classical Latin external arguments can appear below VP adjuncts (Danckaert 2017: 234-235). 
(9)

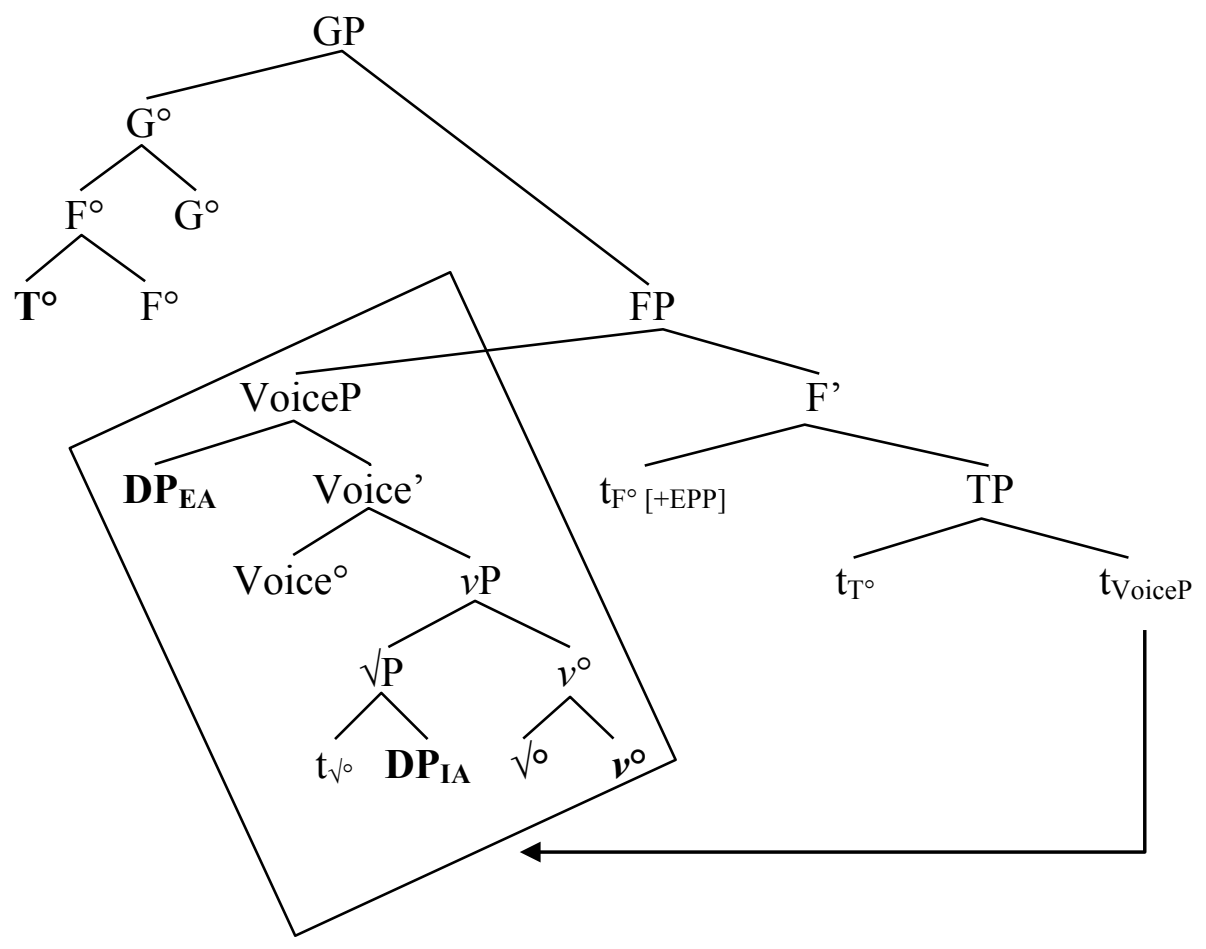

As we will see below, such a structure is often very difficult to distinguish from the output of Grammar B (in which AuxVP-orders can be base-generated), and in actual practice it is impossible to decide on a case to case basis whether a given AuxVP-clause was generated by Grammar A or by Grammar B. Suffice it to say that both grammars could produce similar surface orders, but we can expect auxiliary fronting to be used more often in earlier times.

\subsection{Grammar B}

In order to account for the data summarized in Graph 2 ("loss of VOAux"), it was proposed in Danckaert (2017) that the VPAux output of Grammar A was reanalysed as a (string identical) structure in which the verb phrase and the T-node hosting auxiliaries and synthetic finite verbs are in a more local configuration. More particularly, the details of the proposed reanalysis can be summarized as in $(10):^{12}$

(10) a. [FP [VoiceP S O V ] [F'[EPP] [TP Aux t tooiceP $]]]$

Grammar A

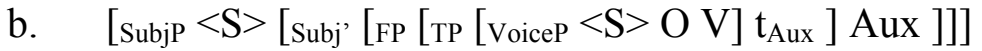

Grammar B

A more detailed structure of a VPAux-clause in Grammar B is given in (11). As indicated, the main difference between Grammar A and Grammar B concerns the way in which the EPP requirement is satisfied: in the new grammar, it is the hierarchically highest verb which head moves to $\mathrm{F}^{\circ}$.

${ }^{12}$ Clauses with only one verb were of course reanalysed in a similar fashion. 


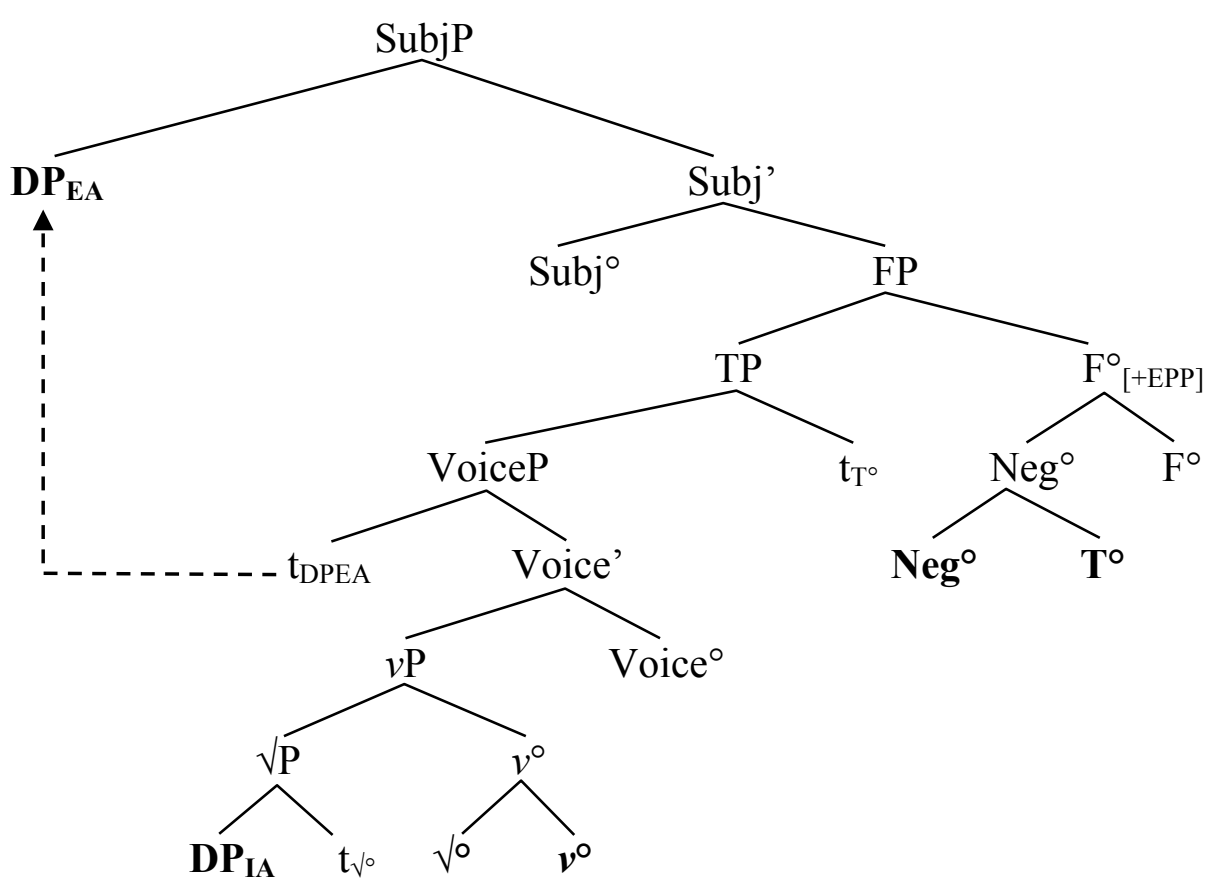

As argued in Danckaert (2017), the ultimate cause of the reanalysis is related to the diachronic development of the preverbal negator. As can be seen in (11), the $\mathrm{F}^{\circ}$-node is occupied by a complex head consisting of $\mathrm{T}$ and a proclitic negator. The reader is referred to Danckaert (2017: 248-252) for additional discussion of the role of negation in bringing about the shift from Grammar A to Grammar B.

Importantly, note that I assume that it is possible for the subject DP (the external argument in a transitive clause) to evacuate the verb phrase and move to a dedicated subject position in the high TP (but lower than the left periphery). I assume that this projection can be equated to Cardinaletti's (2004) SubjP (see also Rizzi 2006). I will come back to the reasons that prompt me to postulate the availability of this additional A-position in Grammar B in section 3.3. In any event, note that in this new grammar all VPAux-orders (abstracting away from left-peripheral VP movement) involve a structure in which VP is dominated by TP (and where TP is dominated by FP). Importantly, such a structure is correctly predicted to be subject to FOFC, and we thus correctly derive the quasi-absence of VOAux-orders in Late Latin (i.e. at the stage in which Grammar B is the dominant grammar).

Given that in Grammar B VP movement is no longer required to arrive at a well-formed syntactic structure, we also expect AuxVP-orders to be available much more freely than in Grammar A. In terms of sheer frequency of occurrence, this does indeed seem to be the case: for instance, in clauses with a modal verb and an infinitive we clearly see that the order "modal-infinitive" becomes more frequent as time goes by (Danckaert 2016, 2017). ${ }^{13}$ One can then think that in Grammar B, the structure of an AuxVP-clause is essentially the same as the one of a VPAux-clause like (11), modulo the headedness of a number of projections in the lower part of the clause (or alternatively, the presence vs. absence of roll-up movement):

\footnotetext{
${ }^{13}$ But as documented in Danckaert (2017: chapter 6), no such increase in AuxVP-orders can be observed in the case of (passive and deponent) BE-periphrases.
} 


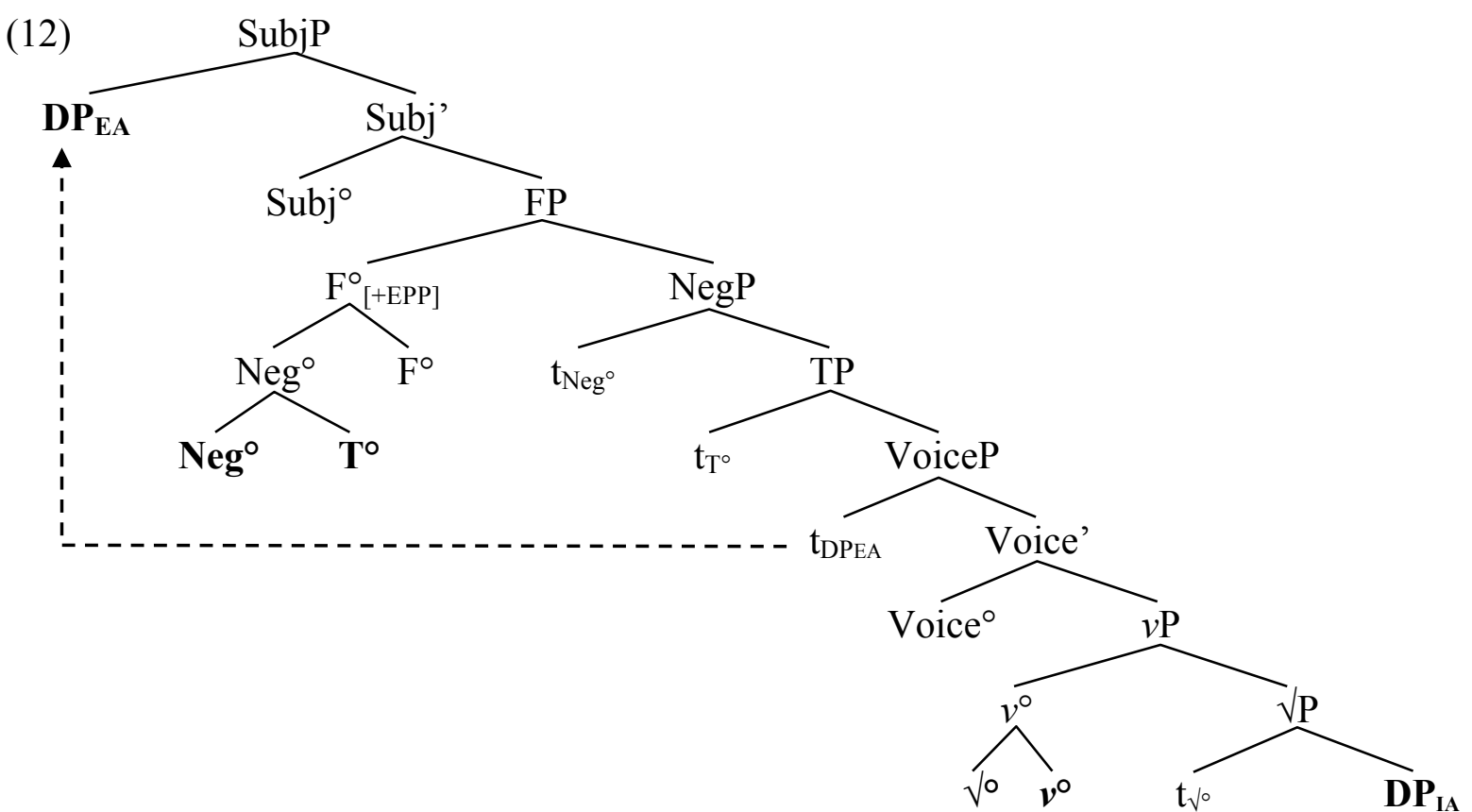

Here too I assume that subjects can optionally undergo A-movement, much in the spirit of Alexiadou \& Anagnostopoulou's (1998) proposals about present day Romance. In the case of Late Latin, there can be little doubt about the non-left-peripheral character of this subject position, given the fact that a preverbal subject typically appears to the right of subordinating conjunctions, which according to Danckaert (2012) can be considered a reliable diagnostic to distinguish left-peripheral from TP-internal material (see also section 5.1.1 on this last point).

As the proposed difference between Grammar A and Grammar B concerning the availability of TP-internal subject positions will play a crucial role in the upcoming discussion, I will now present some evidence in support of this proposal.

\subsection{The distribution of internal arguments in Grammar A and Grammar B}

One interesting contrast between early and later Latin concerns the distribution of internal arguments in active and passive clauses (see also Danckaert 2014). Assuming this contrast to be a reflex of the fact that Grammar A is being replaced by Grammar B, we can hypothesize that the observed contrast is related to the availability of (optional) A-movement for subjects in Grammar B (and the absence thereof in Grammar A).

The basic facts are summarized in Graph 7. The two boxplots on the left show data on placement of direct objects in AuxVP-clauses, which as we have seen is the only environment in which VP-internal (Aux-IA-V) and VP-external (IA-Aux-V) internal arguments can be told apart. The two boxes on the right summarize the corresponding data for internal arguments in passive clauses, i.e. derived subjects. ${ }^{14}$ What is measured is the average rate of the order "IAAux-V", as opposed to the incidence of AuxVP-clauses in which the internal argument appears lower than the auxiliary (i.e. all clauses exhibiting the orders "Aux-IA-V" and "AuxV-IA"):

\footnotetext{
${ }^{14}$ For reasons spelled out in section 2.2, especially in Late Latin it is difficult to obtain reliable results for clauses with a BE-auxiliary, which is why I only consider clauses with a modal verb. For both active and passive clauses I only took into account samples with at least 20 AuxVP-clauses with an overt passive subject.
} 


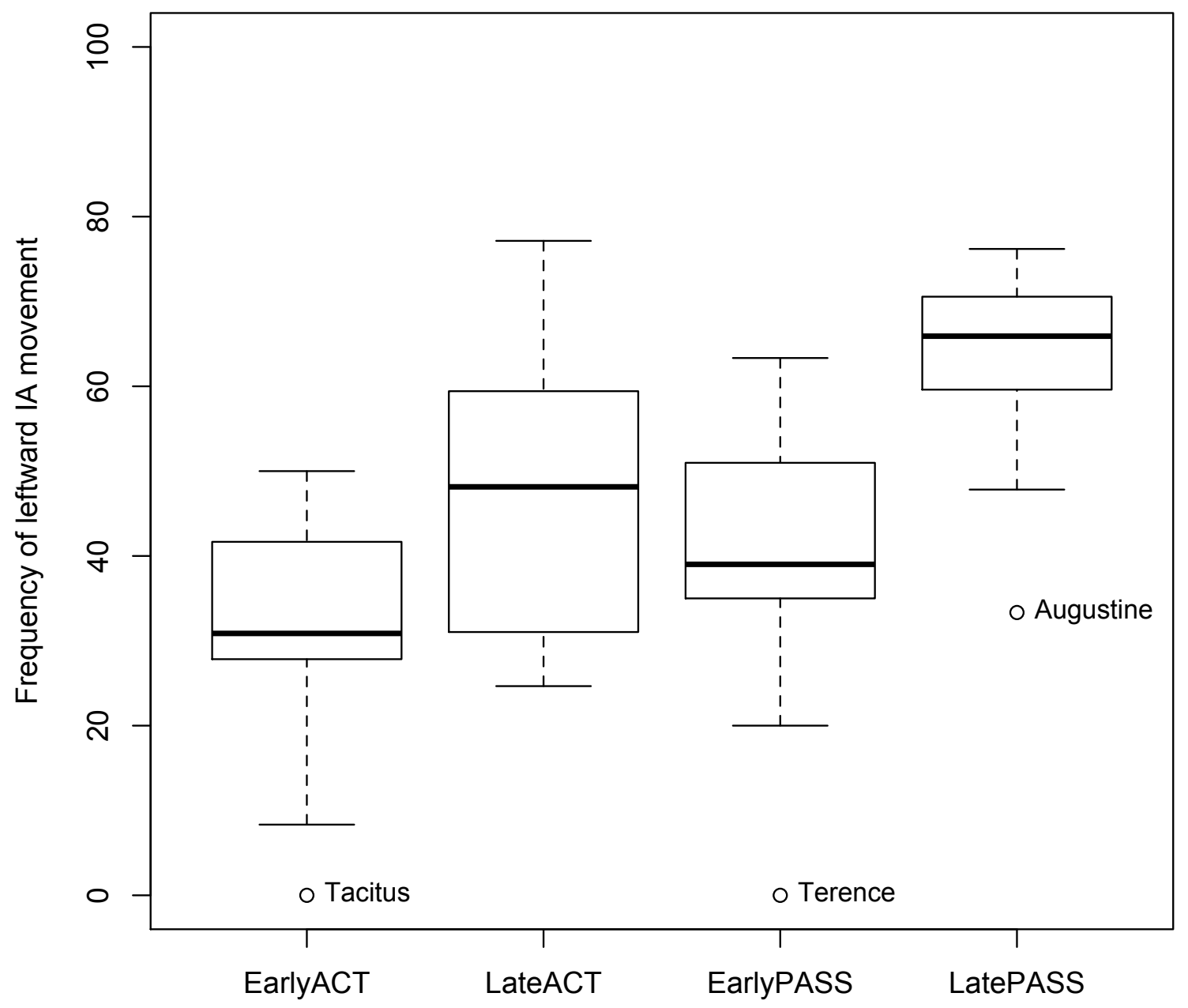

Graph 7: Frequency (in \%) of leftward movement of internal arguments in active and passive clauses.

As we saw earlier, the rate of object shift (OAuxV) increases over time. In Graph 7 we now also see that a similar effect obtains for passive subjects, but apparently a bit more strongly so: whereas there is substantial overlap between the space covered by the two lefthand boxes, no such overlap can be observed for passive subjects, suggesting that in Grammar B subjects evacuate the verb phrase more often than direct objects. The results of a logistic regression corroborate this conclusion. In a model predicting leftward movement of internal arguments in AuxVP-clauses, in which I included Time, Voice (active vs. passive), Type of auxiliary (possum vs. debeo), Type of clause (main vs. embedded) and Type of internal argument (full noun phrases vs. bare demonstrative pronouns) as independent variables, an interaction term between the predictors Time and Voice comes out as significant. The results of the relevant model are summarized in Table 2: 
Table 2: Summary of a logistic model predicting leftward movement of internal arguments in clauses with a modal verb (200 BC - 590 AD).

\begin{tabular}{|c|c|c|c|}
\hline Coefficients: & $\begin{array}{l}\text { Estimate } \\
\text { (log odds) }\end{array}$ & Standard error & $\begin{array}{l}\text { Significant? } \\
\text { (p-value) }\end{array}$ \\
\hline (Intercept) & -0.4946488 & 0.1595408 & $0.001932(* *)$ \\
\hline Time & 0.0007365 & 0.0002026 & $0.000279(* * *)$ \\
\hline Voice:Passive & 0.7272785 & 0.2209584 & $0.000997(* * *)$ \\
\hline Auxiliary:possum & 0.1011143 & 0.1610798 & 0.530182 \\
\hline Clausetype:Main & 0.1118976 & 0.1686109 & 0.506918 \\
\hline IAtype:pronoun & 0.7562841 & 0.1263615 & $2.16 \mathrm{e}-09(* * *)$ \\
\hline Time*Voice:Passive & 0.0009404 & 0.0004226 & $0.026073(*)$ \\
\hline Voice:passive*Auxiliary:possum & -0.4737445 & 0.2189870 & $0.030515(*)$ \\
\hline Auxiliary:possum*Clausetype:Main & -0.9570590 & 0.1925929 & $6.72 \mathrm{e}-07(* * *)$ \\
\hline
\end{tabular}

As can be observed, passive clauses have a higher baseline probability of exhibiting leftward movement of internal arguments. In addition, the overall probability for internal arguments to evacuate the VP increases over time (cf. the positive log odds for the predictor Time). The crucial information can be found in the shaded row, where it is shown that the relative strength of the factor Voice increases over time, in such a way that it gradually favours subject movement more strongly than object movement.

This diachronic effect falls out naturally if we assume that subjects in Grammar B have an additional A-position at their disposal (viz. SubjP), which is not accessible for objects. Note however that this does not yet explain why the rate of object shift increases too: I will come back to this point at the end of section 5 .

Before I return to the competition between the OV and VO grammar, I will first provide some additional details on the particular approach to language change that I will assume, namely the variational acquisition model proposed in Yang $(2000,2002)$.

\section{Yang's variational acquisition model of language change}

As mentioned in the beginning of this paper, I am assuming a grammar competition approach to language variation and change (Kroch 1989, 1995; Pintzuk 1999, 2003). In the case at hand, this approach entails that - presumably at all documented stages of the Latin language - both the OV and the VO grammar, and probably also both Grammar A and Grammar B were part of speakers' linguistic competence. Variation resides in the frequencies at which these two pairs of competing grammars were employed. In addition, it is conceivable that these different grammars were associated with different conditions of usage, although at present very little is known about this type of synchronic variation in Latin.

Yang $(2000,2002)$ provides a probabilistic algorithm to model the dynamics of two or more competing grammars, and to determine how successful a grammar is in parsing the data a language acquiring child is exposed to. ${ }^{15} \mathrm{~A}$ crucial ingredient of his approach is the (among generative linguists very common) assumption that language change is essentially a discontinuous process, whereby a language acquiring child reanalyses (part of) the data that she is exposed to during the critical period, in the sense that she assigns a phrase structure

\footnotetext{
${ }^{15}$ For a recent application of this approach to language change (as well as a very clear exposition of its basic tenets), see Heycock \& Wallenberg (2013).
} 
analysis to a given surface string in the Primary Linguistic Data (PLD) which is different from the representation assumed by the speaker producing the relevant utterance (see Lightfoot 1979 and subsequent literature). In Yang (2000, 2002), each grammar G that a child has access to is taken to be associated with a probabilistic weight, which can be defined as the probability that the child will use $G$ and not one of G's competitors to produce and parse utterances of a given language. More precisely, each time a child chooses grammar $\mathrm{G}_{1}$ and successfully parses a sentence from the PLD, the weight of $\mathrm{G}_{1}$ increases, and concomitantly, the weight of the competing grammar $G_{2}$ decreases. I refer to Yang $(2000,2002)$ for the mathematical details of this proposal.

Assuming a two-way competition between a grammar $\mathrm{G}_{1}$ and a grammar $\mathrm{G}_{2}$, we can distinguish three types of clauses in the PLD: (i) clauses that can only be generated by $\mathrm{G}_{1}$, (ii) clauses that can only be generated by $\mathrm{G}_{2}$ and (iii) clauses that are structurally ambiguous in that both grammars $G_{1}$ and $G_{2}$ can generate them. Yang $(2000,2002)$ then defines the "fitness" of a grammar $\mathrm{G}_{1}$ as the proportion of clauses in the PLD that can only be generated by grammar $G_{1}$. It should be clear that it is data from structurally unambiguous clauses that determine the fitness of a pair of competing grammars.

Finally, we can characterize the "advantage" of a grammar $G_{1}$ over its competitor $G_{2}$ as the fitness of $G_{1}$ minus the fitness of $G_{2}$. Yang's approach predicts that in the long run, the fittest grammar will win out, unless independent factors bring about a change through which the fitness of $G_{1}$ and $G_{2}$ is recalibrated. The author emphasizes that the eventual success of a given grammar does not crucially depend on the initial probabilistic weight of this grammar (say the frequency at which this grammar is used by speakers of a previous generation). Instead, even if a grammar starts out as a very small minority, from the moment that it generates a higher proportion of unambiguous clauses than any of its competitors, it is predicted to stand a good chance to eventually take over from the other grammar.

In what follows, I will apply this system to the competition between the Latin OV and VO grammars introduced in the opening sections of this paper.

\section{Unambiguous evidence for VP-internal object placement}

In order to estimate the fitness of the OV and the VO grammar at various stages of the Latin language, we first have to determine under which conditions both grammars were cued unambiguously. Importantly, these conditions differ quite strongly in the context of Grammar A and Grammar B, which I will therefore treat separately.

Before starting the discussion, let me add the disclaimer that given the remarkable degree of word order flexibility characteristic of Latin (for a brief demonstration, see Danckaert 2017: 3-9), the best one can do is try to control for structural ambiguity as much as possible. For some of the cases that I will take to involve "unambiguous OV" or "unambiguous VO" one could in principle imagine an alternative derivation involving (multiple instances of) remnant movement, but I take it that the criteria that I will use are restrictive enough to arrive at close enough an approximation of the actual rates of unambiguously VP-internal OV and VO.

\subsection{Cueing object placement in Grammar A}

\subsubsection{The OV grammar}

I will start by looking at unambiguous evidence for the OV grammar in a Grammar A setting. Recall that the basic structure for a transitive clause was proposed to look like (13), with EPP-driven VP movement to SpecFP, leaving all the verb's arguments in situ (that is, 
whenever these arguments do not further move to a specialized scope-discourse position above FP).

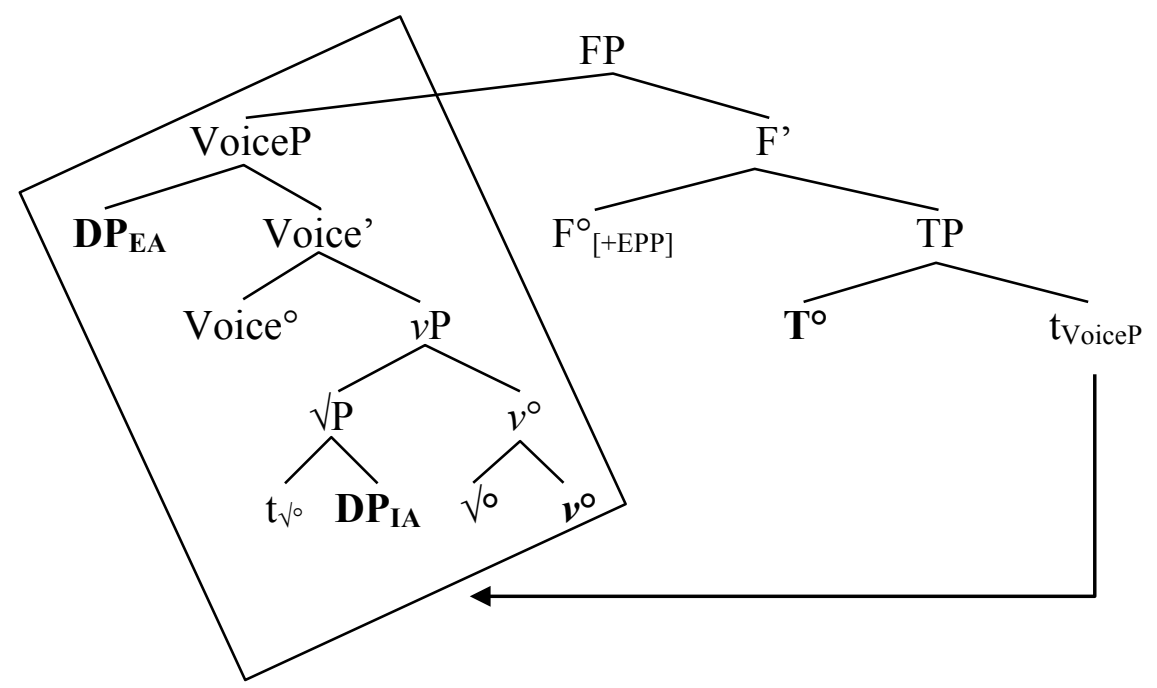

So under which conditions could the language learner be confident that a given OVsequence was generated by the OV grammar? First of all, note that it is not necessary for there to be strict linear adjacency between $\mathrm{O}$ and $\mathrm{V}$ : depending on certain details concerning the articulation of the inner layers of the verb phrase, and in particular the way in which the various elements in a complex verb phrase are linearized, it is conceivable that for instance an indirect object DP or a PP argument ends up in between $\mathrm{O}$ and V. However, in order for a given direct object to be VP-internal, no material should intervene between $\mathrm{O}$ and $\mathrm{V}$ which we can be sure to be first merged higher than $v \mathrm{P}$ : such an element would indicate that the direct object has evacuated the thematic domain.

Let us first of all assume that external arguments are always first merged higher than internal arguments (given some version of UTAH). If so, the presence of a(n overt) preverbal external argument in an OVAux-clause could in principle serve as a diagnostic to signal the upper boundary of the thematic domain, and by this token it could constitute evidence for the VP-internal position of a given direct object. Needless to say, this can only be possible if the subject itself sits in its base position. In other words, what we need is the presence of an unambiguously non-left-peripheral preverbal subject to the left of $\mathrm{O}$ in an OV-clause. There are two diagnostics to further determine the exact location of a given subject argument (in the $\mathrm{CP}$, TP or VP-layer), namely (i) subordinating conjunctions and question words in root interrogatives and (ii) (finite) auxiliaries.

As to the first, $w h$-words and conjunctions like cum 'when' and si 'if' can be taken to be located at the lower edge of the left periphery (FinP according to Danckaert 2012). By this token, any subject DP appearing to the left of such an element, such as Caesar 'Caesar' in (14), must be located in the left periphery (cf. (15)). ${ }^{16}$ Given the islandhood of (tensed) adverbial clauses, we can be confident that the fronted element does indeed sit inside the embedded clause, and not in the superordinate domain.

${ }^{16}$ Observe that the structure in (15) involves subextraction from a subject (complex specifier). As shown in Haegeman, Jiménez-Fernández \& Radford (2014), although restricted under certain conditions, this operation is not categorically banned. 


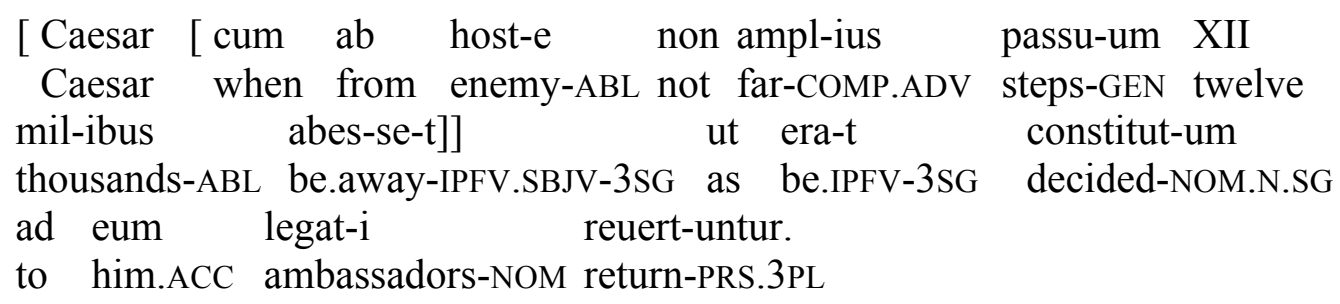

'When Caesar was less than twelve miles away from the enemy, the ambassadors returned to him, as had been determined.' (Caes. Gal. 4.11)

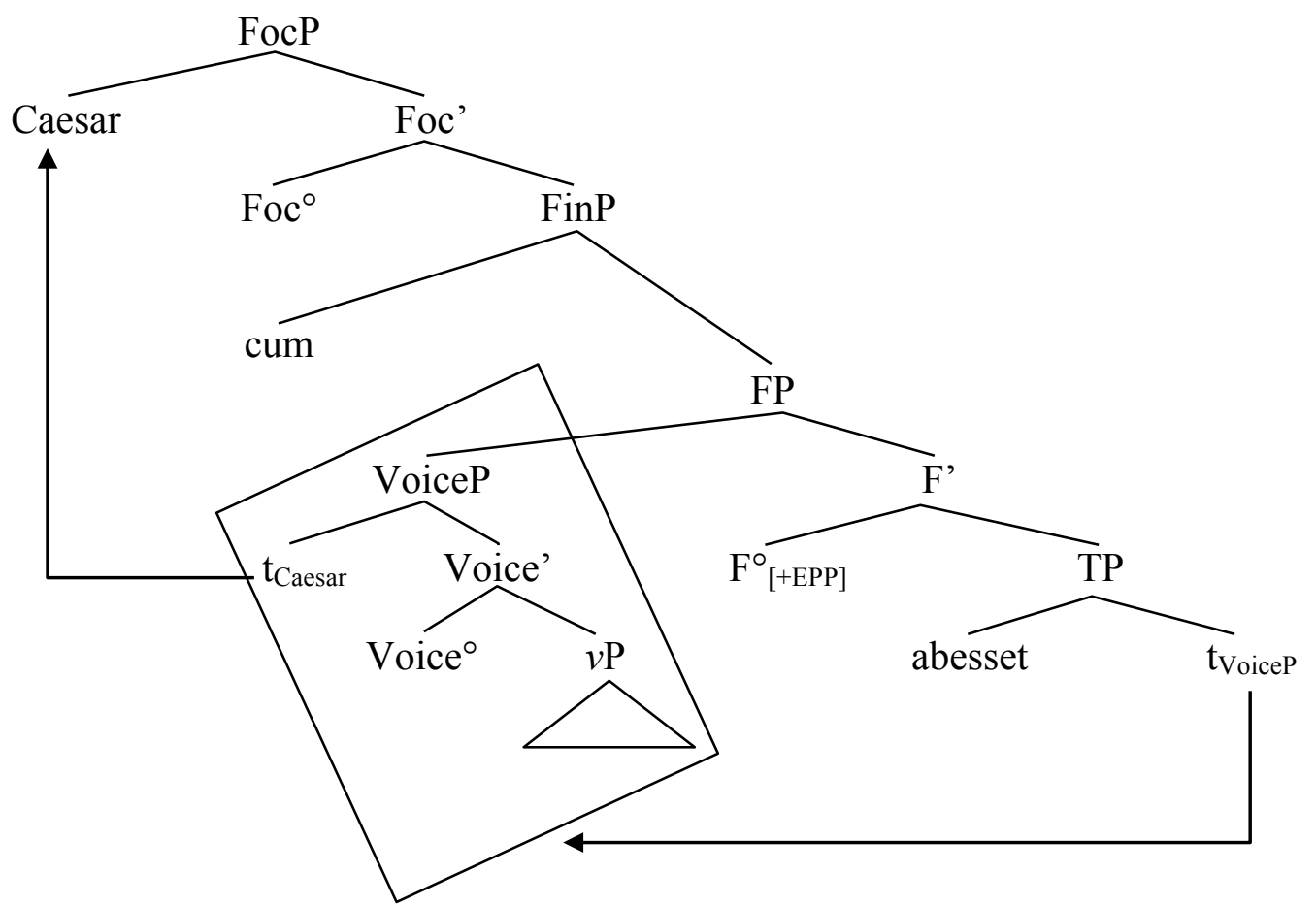

On the other hand, all subjects appearing lower than a clause-introducing element must be non-left-peripheral. Moreover, given that Grammar A does not have A-movement for subjects (i.e. movement targeting a position somewhere in the articulated T-field), all nonleft-peripheral subjects should be VP-internal, and should therefore be a reliable diagnostic to identify VP-internal objects. For instance, for the specific case of an embedded OV-sequence like (16), in which the external argument intervenes between $\mathrm{O}$ and $\mathrm{V}$, we can be sure that the direct object must have been displaced to a position higher than VoiceP:

$$
\begin{array}{lllll}
\text { sed } & \text { si=ue fund-um locuple-s mercat-us } & \text { est } \\
\text { but if }=\text { or } & \text { farm-ACC } & \text { rich-NOM.M.SG bought-NOM.M.SG be.PRS.3SG } \\
\text { 'but if a rich man has bought a farm' (Col. 1.praef.12) } &
\end{array}
$$

OSVAux

A possible representation of such a clause is given in (17), where the shifted direct object fundum 'farm' appears in the specifier of a projection that I've simply labelled ObjP (for want of a better label). Importantly, it is impossible to decide whether the input structure of this derivation involves a right-headed or a left-headed $\nu \mathrm{P}$, and therefore such examples are uninformative for the language learner when it comes to assessing the fitness of the OV and the VO grammar. 
(17)

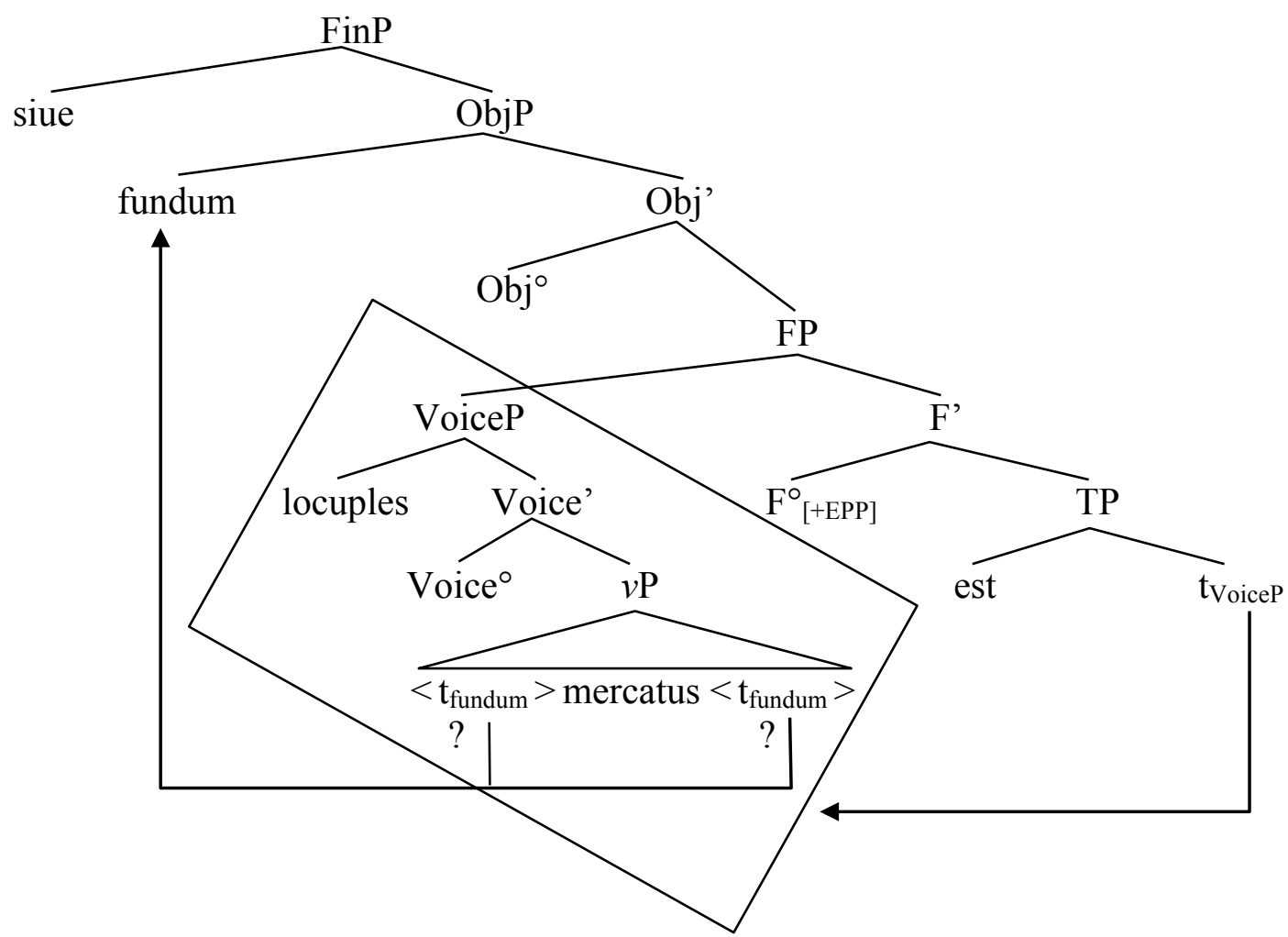

The second diagnostic which can identify a non-left-peripheral subject as such is a preVP auxiliary. This is so because the hierarchically highest verb (usually the finite verb) of a clause can never appear in the left periphery of the clause (Danckaert 2012: 275). ${ }^{17}$ From this it follows that any subject DP to the right of an auxiliary should itself be non-left-peripheral too, and in a Grammar A setting, it would then be VP-internal. ${ }^{18}$ In AuxVP-clauses of the Grammar A type, all AuxSOV-sequences would then constitute unambiguous evidence for the OV grammar. In contrast, AuxOSV-clauses such as (18) would involve object movement of the same type as in (17) (with subsequent auxiliary fronting, as in (9)). As a result, AuxOSV-clauses too would not provide the language learner with any unambiguous evidence in favour of the OV or the VO grammar. ${ }^{19}$

Non, inquam, iudic-es, $\quad$ es-se-t $\quad$ [ull-am part-em
not say.IPFV.1SG judges-VOC be-IPFV.SBJV-3SG any-ACC part-ACC
ist-ius $\quad$ nequiti-ae $] \quad$ [fugitiu-orum insolenti-a] consecut-a.

${ }^{17}$ As clauses with more than one element that one could reasonably describe as "auxiliaries" are increasingly rare in Latin (basically restricted to clauses in which the two modals debeo and possum (always in this order) co-occur, and combinations of an epistemic modal and an infinitival BE-periphrasis), an auxiliary will almost always be the hierarchically highest verb in the clause in which it appears.

${ }^{18}$ Given the present analysis, all CSAuxVP-clauses, i.e. clauses in which a non-left-peripheral subject has unambiguously evacuated the VP, must have been generated by Grammar B, constituting a case in which AuxVP-clauses are not ambiguous between a Grammar A and a Grammar B parse.

${ }^{19}$ Observe that the type of object movement which is at work in an example like (18) is different from the type of object shift found in OAuxV-clauses which was discussed in section 2.2.2 (landing site below or above T). In section 5.1.2.3 I will return to the syntax of various types of (non-left-peripheral) object movement. 
that-GEN.M.SG depravity-GEN fugitives-GEN insolence-NOM obtained-NOM.F.SG

'As I said, gentlemen, the insolent fugitives would not have committed a fraction of this man's crimes.' (Cic. Ver. 3.66)

To sum up, in Grammar A the strings CSOVAux and AuxSOV should constitute environments in which the language learner can be confident that an OV-sequence is generated by the OV grammar (or put differently, that the direct object is VP-internal). All other linear OV-orders are either ambiguous, or unambiguously involve a VP-external object.

\subsubsection{The VO grammar}

Let us then consider under which conditions the VO grammar could be cued in a Grammar A setting. Whereas matters are fairly straightforward in VPAux-clauses, the correct analysis of object placement in AuxVP-clauses is far more problematic.

\subsubsection{VOAux}

Unambiguous instances of VP-internal VO can first of all be found in clauses in which a VO chunk appears to the left of the auxiliary, which instantiate the type of apparent violation of FOFC which is only possible in Grammar A, as discussed earlier. I shall take it that various types of VOAux-clauses unambiguously cue the VO grammar, regardless of whether the three elements involved are string adjacent or not. For instance, alongside SVOAux( and VOAuxS)-sequences, clauses with the order VOSAux (which arguably involve movement of $v \mathrm{P}$ to some position past VoiceP prior to movement of VoiceP to SpecFP) would also provide the language learner with sufficient evidence to postulate that a given token was generated by the VO grammar.

As mentioned, the analysis of clauses in which the direct object follows the auxiliary is less straightforward. As I will argue in the following sections, post-Aux direct objects can either involve (i) genuine VP-internal VO, (ii) extraposition (in a sense to be made more precise) or (iii) short-distance scrambling followed by remnant movement.

\subsubsection{Two different VAuxO patterns}

As a starting point earlier in this paper (section 2.2.1), I took it that VAuxO-clauses involve object extraposition, and that clauses featuring the order AuxVO are in principle ambiguous between a structure with a VP-internal object and one in which the object is extraposed. As I will now proceed to show, one has to make a further distinction between (at least) two different types of non-local VO. I will illustrate this point by looking at VPAuxclauses, as in this environment we can most easily tell apart local from non-local VO patterns, but both types of non-local VO are available in AuxVP-clauses too.

In the informal characterization of extraposition offered earlier, it was mentioned that only those direct objects that occur in an absolute clause-final position can in principle qualify as extraposed. However, it is certainly not the case that in all AuxVO-clauses no additional (clausemate) XP occurs to the right of the object. For instance, whenever we find the linear sequence VAuxO, a post-Aux subject (in boldface) can either immediately precede (19) or follow (20) the direct object:
Ita ut censu-era-t
Quincti-us
fec-erunt,
thus as recommend-PLPRF-3SG
nec aspernat-us
est
Quinctius-NOM
do-PRF.3PL
consul legation-em.

and.not scorned-NOM.M.SG

'They acted as Quinctius had recommended, and the consul did not reject the 
delegation.' (Liv. 36.35.6)

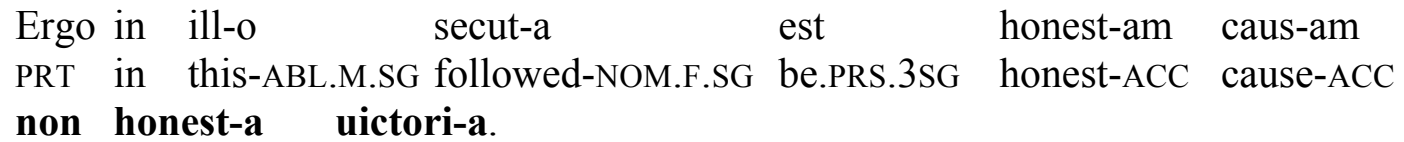

not honest-NOM victory-NOM

'So in his (Sulla's ld) case an ill-deserved victory has followed a just cause.' (Cic. Off. 2.27)

The problem with examples like (20) is that it is on the one hand certain that the object honestam causam 'a just cause' does not sit inside the verb phrase, but on the other hand, it also doesn't occur in a clause-final position. If we are to maintain that extraposed constituents obligatorily occur in an absolute clause-final position (an assumption that would also imply that per clause only one constituent can be extraposed), it would follow that not all objects in VAuxO-clauses are extraposed. But can we really make a strong case for the claim that extraposed objects should appear at the very end of a clause?

\subsubsection{The syntax of postposed objects}

In order to answer this last question, it is first of all important to note that what I have informally been calling "extraposition" in fact corresponds to a number of distinct syntactic phenomena. On the one hand, there are certain types of extraposition which can be iterated, and therefore do not qualify as processes that invariably put a given constituent at the absolute end of a clause. Such is the case with extraposition of relative clauses, as well as with extraposition of PPs associated with a nominal constituent. ${ }^{20}$ For instance, in both English (21a) and Dutch (21b) it is possible for more than one extraposed relative clause to be associated with a single antecedent (examples from Keller (1995: 302) and de Vries (1999, his (14a)); see also Guéron \& May (1984: 28)):

(21) a. A paper just came out [which talks about extraposition] [which you might be interested in].

b. Ik heb de man gesignaleerd [die je beschreef], I have the man noticed who you described [die een rode koffer draagt]. who a red suitcase carries

'I have noticed the man who you described, who carries a red suitcase.'

In addition, in (my own variety of) Dutch multiple PPs can be extraposed from one single noun phrase (cf. (22d)). (22b-c) show that the two PPs are indeed two separate constituents):

(22) a. Ik heb [een man [uit Rusland] [met vier gouden tanden]]gezien. I have a man from Russia with four golden teeth seen 'I saw a man from Russia with four golden teeth.'

b. ' Ik heb [een man [met vier gouden tanden]] gezien [uit Rusland].

c. Ik heb [een man uit Rusland] gezien [met vier gouden tanden].

d. Ik heb [een man] gezien [uit Rusland] [met vier gouden tanden].

\footnotetext{
${ }^{20}$ Note that extraposition of relative clauses and extraposition of PPs are themselves two distinct syntactic phenomena (Fox \& Nissenbaum 1999; Sheehan 2010).
} 
These data clearly show that there is no requirement for extraposed relative clauses and PPs to appear at the very right edge of a clause (in whatever way these structures are to be analysed).

On the other hand, the syntax of extraposed (right-peripheral) subjects and objects seems to be very different. ${ }^{21}$ As is well known, in contrast with extraposed relative clauses and PPs, postposed argument DPs are typically prosodically heavy (and/or internally complex), and usually also focalized. The most famous member of this family of phenomena is no doubt Heavy Noun Phrase Shift (HNPS) in English, which has a clear tendency to appear at the very end of a clause. ${ }^{22}$ For instance, as argued by Svenonius (1992), objects that have undergone HNPS obligatorily follow all other VP-internal material, and thus differ from non-heavy objects which are separated from the lexical verb only by a particle (examples from den Dikken 1995: 87, his (131)). As den Dikken points out, an example like (23c), in which a direct object appears at the end of the clause and to the right of a postverbal adjunct, only becomes acceptable if the direct object is sufficiently heavy.

(23) a. They set the bomb off [with a transmitter].

b. They set off the bomb [with a transmitter].

c. $\quad *$ They set off [with a transmitter] the bomb.

But then what about the relative position of a shifted heavy object and two postverbal adjuncts? ${ }^{23}$ As it turns out, speakers have a preference for the shifted object to appear at the very end of the clause, as in (24):

(24) I met [pP on the street] [DP last Monday] [DP my rich uncle from New York].

To the extent that any adjunct can appear after a heavy shifted object (some of the speakers that I consulted reject this pattern, but see footnote 23), the additional adjunct is always destressed, whereas it is the object that receives focal stress. For instance, (25) can only be (marginally) acceptable when last Monday is delivered with flat intonation, which plausibly indicates that the clause-final adjunct is not properly integrated in the same clause as the heavy object, but rather right-dislocated.

(25) \% I met [pP on the street] [DP my rich uncle from New York] [DP last Monday].

Assuming a coordination analysis to (backgrounding) right-dislocation, as in Ott \& de Vries (2016), ${ }^{24}$ it would be possible to maintain that a HNPS constituent always appears in an absolute clause-final position.

\footnotetext{
${ }^{21}$ Compare also the discussion in Pintzuk \& Kroch (1989).

${ }^{22}$ In their discussion of a number of postposition phenomena, Huddleston \& Pullum (2002: 1382) note that "[a]n element is said to be postposed when it appears to the right of its basic position, at the end of the clause (save perhaps from one or more adjuncts)". They do not given any examples in which 'one or more adjuncts' follows for instance an object that has undergone HNPS, but see the discussion of (24) and (25) below.

${ }^{23}$ At least in English, it does not seem possible to test whether HNPS is compatible with extraposition (of PPs and relative clauses) from nominal constituents, given that these operations are generally blocked by the presence of a (fully referential) direct object (on this effect with PP extraposition, see Guéron 1980: 663-664).
} 
Facts similar to the ones concerning HNPS in English also hold for one particular type of VS-orders in French, which Lahousse (2006) calls "focus inversion" (26). This type of inversion is distinct from "genuine" subject-verb inversion, where the subject remains in its base position. As the author shows, in cases of French focus inversion a postverbal subject cannot be followed by for instance a PP, witness the ungrammaticality of (26b) (examples from Lahousse (2006: 426, 453), based on Kampers-Manhe, Marandin, Drijkoningen, Doetjes \& Hulk (2004)):

(26) a. Pass-er-a [pP devant le conseil de discipline] [DP tout élève de go-FUT-3SG before the committee of discipline every pupil of 1' établissement au comportement incivil]. the institution with.the behaviour inappropriate.

'Every pupil of the school with inappropriate behaviour will appear before the disciplinary committee.'

b. *Passera [DP tout élève de l'établissement au comportement incivil] [pP devant le conseil de discipline].

Here I will not further analyse the syntax of these two types of argument extraposition: the reader is referred to Lahousse (2006) and Wallenberg (2015) for more detailed discussion.

\subsubsection{Two types of VP-external VO configurations in Latin}

Given this more fine-grained typology of extraposition phenomena, we can now try to analyse the contrast between the Latin data in (20) (clause-final vs. non-clause-final object in VAuxO-clauses). What I would like to propose is that one has to distinguish two types of VAuxO-clauses, one involving extraposition akin to English HNPS, and one involving (shortdistance) object scrambling followed by (EPP-driven) movement of a remnant VP (a series of operations which typically yields the same surface order as application of HNPS). The former is predicted to typically feature heavy and/or focalized direct objects, whereas no such weight effect is expected in the latter case.

One advantage of this proposal is that it allows us to make sense of the observation that not all direct objects in VAuxO-clauses are prosodically heavy (however the notion of prosodic weight is exactly operationalized). Recall from section 2.2.1 that direct objects that follow a VAux-sequence can either be short or long. Two examples are repeated here for convenience:

$$
\begin{aligned}
& \text { a. Tot uad-ibus accusator uadat-us } \\
& \text { so.many guarantees-ABL prosecutor.NOM admitted.to.bail-NOM.M.SG } \\
& \text { est re-um. }
\end{aligned}
$$

be.PRS.3SG accused-ACC

'With so many guarantees the prosecutor admitted the accused to bail.' (Liv. 3.13.8)

\footnotetext{
${ }^{24}$ As pointed out in Ott \& de Vries (2016), backgrounding right dislocation can affect XPs of various categories, including adverbs, in which case no co-indexed correlate is needed in the preceding clause.
} 
b. Complex-us es [funest-um illud animal

embraced-NOM.M.SG be.PRS.2SG deadly-ACC this.ACC.N.SG animal.ACC

ex nefari-is stupr-is, ex civil-i cruor-e,

out.of horrible-ABL sexual.misconduct-ABL out.of civil-ABL blood-ABL

ex omn-i sceler-um inportunitat-e concret-um].

out.of all-ABL crimes-GEN relentlessness-ABL composed-ACC

'You embraced this deadly monster, composed of horrible misconduct, civil bloodshed, and all sorts of perverse crimes.' (Cic. Pis. 21)

In the second example, the clause-final direct object is clearly very long, and internally complex: this seems like a good candidate to instantiate genuine object extraposition, of the type that favours prosodically heavy constituents, and requires the extraposed element to appear in an absolute clause-final position.

In contrast, (27a) can be assumed to have a very different syntax. Given that the direct object reum 'the accused' in this example is clearly very short, and given that this element refers to a well established discourse referent (viz. the murderer Caeso), whose vicissitudes have been under discussion for quite a while at the point where (27a) is added to the discourse, it seems reasonable to assume that this direct object has been scrambled out of the verb phrase, to a fairly low position just above the thematic nucleus of the clause, before the remnant VP moves to SpecFP. The relevant structure would look as in (28), where the landing site of the object is called "ScrP", to borrow a label from Devine \& Stephens (2006):

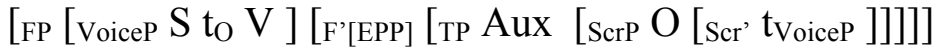

Let us at this point take stock. Recall that we are ultimately concerned with AuxVOclauses, and that we want to know under which conditions the language learner could be confident that these involve a VP-internal rather than a VP-external object. We have also seen that there are two types of VP-external VO, one involving HNPS ("extraposition") and one involving short scrambling. Note first of all that the only type of derivation in which this last operation could give rise to the order $\operatorname{Aux}(\mathrm{S}) \mathrm{VO}$ involves short object movement, followed by remnant VoiceP movement and finally an additional step of auxiliary raising (plausibly of the type detailed in (9)). Given the complexity of this derivation, we can assume that this pattern should be rare. On the other hand, a HNPS analysis of AuxVO-clauses seems more likely, even if the object is followed by an additional (right-dislocated) XP. In a Grammar A setting the string AuxVOXP would then be three-ways ambiguous between (i) a structure in which a heavy shifted object is followed by a right-dislocated XP, (ii) one involving a VP-internal object followed by a right-dislocated XP and (iii) one with a VP-internal object followed by a clausemate XP. Needless to say, telling apart these three possible structures is not at all a trivial task.

In order to maximally ensure that I correctly distinguish VP-internal objects from cases that can in principle involve a VP-external object (and which are therefore not informative about the OV/VO alternation proper), I first of all decided to classify as "ambiguous" all VO clauses in which the object appears at the very right edge of the clause. Of the remaining AuxVOXP-clauses, I classified as "unambiguous" only those cases in which the object is relatively short, that is, if it is either (i) a one-word expression (33 tokens in my corpus), (ii) a noun modified by a single adjective or genitive (12 tokens), or (iii) a pair of two coordinated (single word) noun phrases ( 1 token). In addition, I excluded all cases where there can be reasonable doubt that the XP following the direct object is part of the same clause as the VOsequence: for instance, I left aside all cases where the only element after a VO string is an 
adverbial clause, which might very well not be fully syntactically integrated in the clause to its left.

\subsubsection{Summary}

I conclude this section with an overview of possible patterns of linear VO orderings (Table 3, where the \#-sign stands for the right edge of a clause). I take it that only the two patterns in the shaded rows (VO in VPAux-clauses, and one type of VO in AuxVP-clauses) constitute unambiguous evidence for the VO grammar in a Grammar A setting.

Table 3: VO patterns in Grammar A.

\begin{tabular}{|c|c|l|}
\hline Word order pattern & Possible parses & \multicolumn{1}{|c|}{ Type of object placement } \\
\hline VAuxO\# & 2 & $\begin{array}{l}\text { - short scrambling + remnant } \\
\text { movement } \\
\text { - HNPS (extraposition) }\end{array}$ \\
\hline AuxVO\# & $2(3 ?)$ & $\begin{array}{l}\text { - VP-internal VO } \\
\text { - HNPS (extraposition) } \\
\text { (- short scrambling + remnant } \\
\text { movement + Aux raising?) }\end{array}$ \\
\hline $\begin{array}{c}\text { AuxVO } \\
\text { is not an adverbial clause) }\end{array}$ & 1 & \begin{tabular}{l} 
- VP-internal VO \\
\hline VOAux
\end{tabular} \\
\hline
\end{tabular}

\subsection{Cueing object placement in Grammar B}

\subsubsection{The VO grammar}

Let us then consider how the OV and the VO grammar can be cued in Grammar B. As to the latter, given that neither the syntax of VP-internal VO (a head-initial $v \mathrm{P}$ ) nor the syntax of HNPS/extraposition (whatever its exact nature) are in principle affected by the shift from Grammar A to Grammar B, nothing changes with respect to the way in which the VO grammar is cued in AuxVP-clauses. However, given that VPAux-clauses no longer involve non-local VP movement, but rather a structure which is subject to FOFC (namely one whereby the top segment of the T-projection dominates the entire verb phrase), in Grammar B it is no longer possible to generate VP-internal VO whenever the T-node is head-final. Put differently, it must be the case that all cases of VOAux found in Late Latin texts were generated by the declining Grammar A.

\subsubsection{The OV grammar}

On the other hand, given the major change that took place with respect to the syntax of preverbal subjects, the conditions under which the language acquirer can be confident that a given OV string was generated by the OV grammar are very different in Grammar A and Grammar B. However, here too the differences are confined to VPAux-clauses.

Consider first the structure of an AuxVP-clause with an overt subject and object as generated by Grammar B. (29) shows the derivation of a negated clause, where the finite verb (with a proclitic negator attached to it) winds up in $\mathrm{F}^{\circ}$ : 
(29)

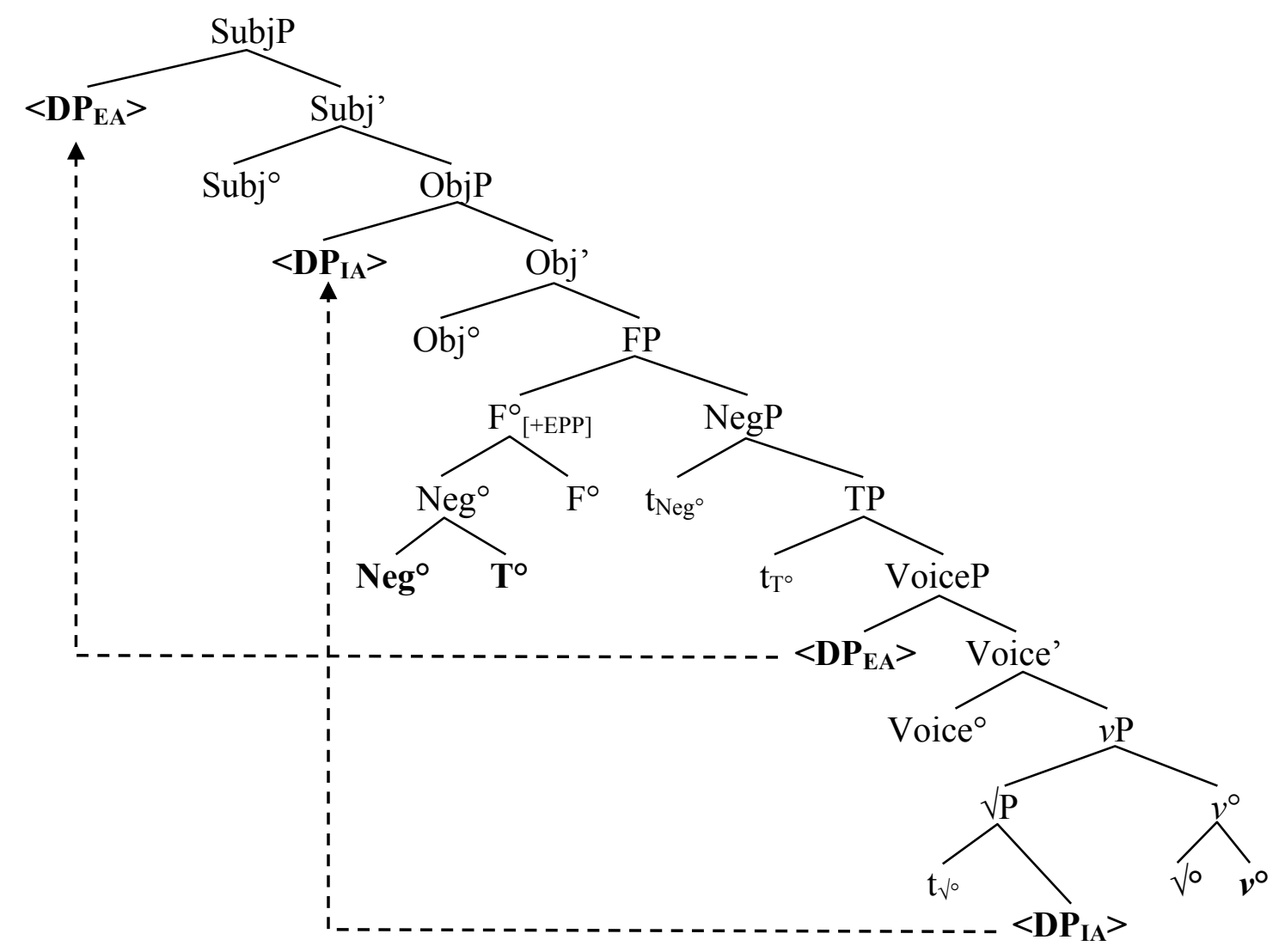

(29) represents the structure of an AuxVP-clause with a transitive predicate, and two possible positions for the direct object ${ }^{25}$, as well as two possible positions for the subject. ${ }^{26}$ As to the former, both the VP-internal pattern of object placement and the pattern of object shift were available in Grammar A too: I assume that Grammar B behaves exactly the same in this respect. What is new is the possibility for subjects to undergo A-movement (by assumption to SpecSubjP). As mentioned, the conditions under which VP-internal OV can be cued are the same as in Grammar A (modulo the different positions for the auxiliary in Grammars A and $\mathrm{B})$ : whenever neither the auxiliary nor the subject intervenes between $\mathrm{O}$ and $\mathrm{V}$, and whenever the subject remains in its base position (i.e. surfaces to the right of the auxiliary but to the left of $\mathrm{V}$ ), the child is presented with sufficient evidence to postulate that the a given OV string involves a VP-internal direct object. Put differently, the word order AuxSOV serves as a cue for the OV grammar. ${ }^{27}$

\footnotetext{
${ }^{25}$ Note that I am abstracting away from the short-distance object scrambling pattern (which in an AuxVP-clause would yield the order $\operatorname{AuxO}(\mathrm{S}) \mathrm{V})$ discussed above.

${ }^{26}$ As a reviewer points out, in order for it to be possible for the subject to move across a shifted object, one would have to assume that the latter does not count as an intervener for the former. Although it remains to be seen how exactly the relevant facts are to be accounted for 'locality-wise', it seems to be the default case that whenever two of a verb's arguments simultaneously evacuate the VP to move to the TP-layer, the argument with the higher base position also targets the higher TP-internal position. For early discussion of such 'order preservation' effects in the middle field, see Haegeman (1993a,b).

${ }^{27}$ Note however that this - perhaps not innocuously - presupposes that in Grammar B there is no auxiliary fronting past SubjP (and possibly a subject in SpecSubjP): if such an operation could be shown to exist, then AuxSOV-clauses would in fact not unambiguously cue the OV grammar.
} 
Crucially, the situation is very different in VPAux-clauses. A basic structure for this type of clause in Grammar B is given in (30), where again two possible positions for direct objects (in situ or shifted) are indicated, as well as two positions for the subject (in situ or Amoved):

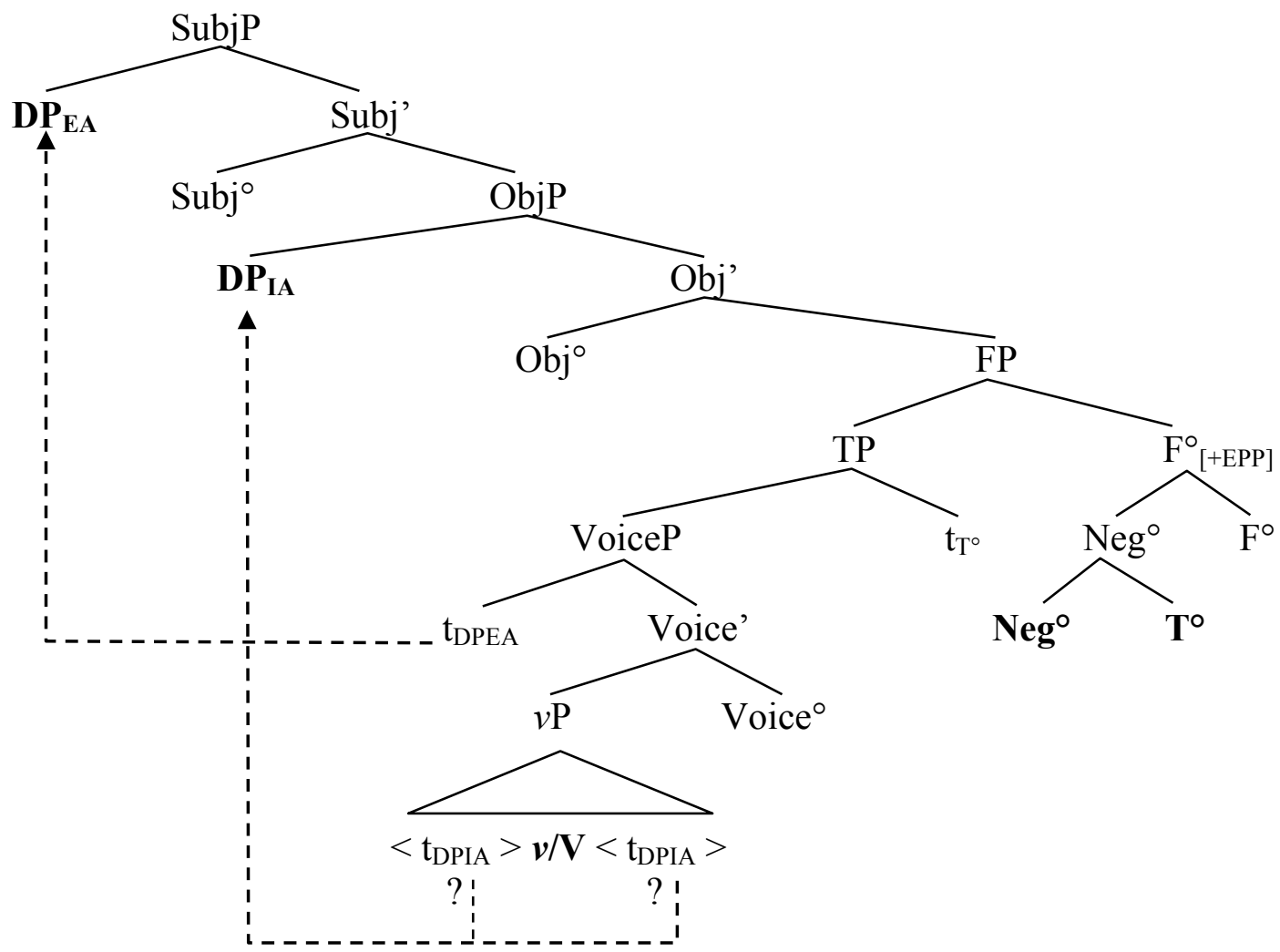

The crucial observation is that whenever the subject moves to SpecSubjP, application of object shift (or of short-distance scrambling, for that matter) becomes string vacuous, and as usual, whenever a parse involving object shift is available, it is impossible to tell whether the structure involves a left or a right-headed $v \mathrm{P}$. As a result, even if a given preverbal subject in an SOVAux-clause appears lower than a subordinating conjunction or wh-word (which excludes an analysis involving a left-peripheral subject), it is still impossible for the language learner to determine whether the subject is in SubjP or in VoiceP, and by this token, the status of the direct object (in situ or shifted) also becomes ambiguous. As we will see in the final part of this paper, this state of affairs has major consequences for the fitness of the OV grammar in Grammar B.

\subsection{Object shift revisited}

The main results of section 5 are summarized in Table 4. As can be seen, in Grammar $\mathrm{B}$, both the OV and the VO grammar can be cued unambiguously in fewer environments (cf. the underscored word order patterns in the Grammar A column). 
Table 4: Cues for the OV and the VO grammar: summary.

\begin{tabular}{|l|l|l|}
\cline { 2 - 3 } \multicolumn{1}{c|}{} & \multicolumn{1}{c|}{$\begin{array}{c}\text { Grammar A (roughly early } \\
\text { period, 200 BC - 200 AD) }\end{array}$} & \multicolumn{1}{c|}{$\begin{array}{c}\text { Grammar B (roughly late } \\
\text { period, 201 - } \mathbf{6 0 0} \text { AD) }\end{array}$} \\
\hline OV grammar & CSOVAux, AuxSOV & AuxSOV \\
\hline VO grammar & $\begin{array}{l}\text { VOAux, AuxVOXP (where XP } \\
\text { is not an adverbial clause) }\end{array}$ & $\begin{array}{l}\text { AuxVOXP (where XP is not an } \\
\text { adverbial clause) }\end{array}$ \\
\hline Ambiguous & all other word orders & all other word orders \\
\hline
\end{tabular}

What I will suggest in section 6 is that it was the fact that the string CSOVAux at a certain point became structurally ambiguous which dealt the fatal blow to the OV grammar. More particularly, despite having a fairly high token frequency (see below), in Grammar B this type of clause does not provide the language learner with any reliable clues to determine the exact structural position of subjects and objects.

Interestingly, this hypothesis might help us to understand the observation made earlier concerning the diachronic development of object shift, and more particularly the increasing frequencies of the order OAuxV (cf. section 2.2.2). Recall from section 3.2 that the transition from Grammar A to Grammar B was argued to involve reanalysis of VPAux-clauses like (31a) as the structure in (31b). Note however that as things stand, this simple scenario does not explain why the rate of object shift increases over time.
a. $\quad\left[\right.$ FP $[$ VoiceP $\mathrm{S}$ O V $]\left[\mathrm{F}^{\prime}[\mathrm{EPP}]\left[\mathrm{TP}\right.\right.$ Aux t $\left.\left.\left.\mathrm{V}_{\text {oiceP }}\right]\right]\right]$
Grammar A, OV

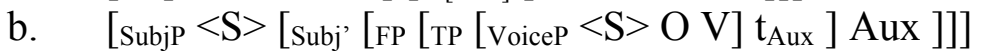
Grammar B, OV

Given that in Grammar B, there is no longer one single non-left-peripheral position for preverbal subjects, we can speculate that the output of Grammar A (OVAux and VOAux) was not simply reanalysed as $(31 \mathrm{~b})$, which contains only one object position. More precisely, in the context of Grammar B there does not seem to be robust enough evidence to postulate one single "default" position for preverbal direct objects, as (31b) suggests. Instead, we can assume the following structure to be the target of reanalysis:

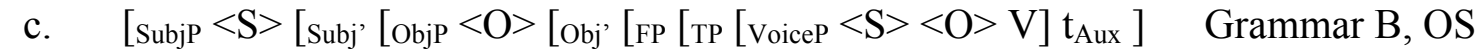

$$
\begin{aligned}
& \text { Aux ]]]]] }
\end{aligned}
$$

As can be seen, this structure not only contains two subject positions, but also two object positions (viz. one inside VP and one above TP which hosts shifted objects), both of which are also available in Grammar A. ${ }^{28}$ The idea would be that VP-internal direct objects in OVAux and VOAux strings generated by Grammar A were reanalysed either as shifted or as VP-internal (but always preverbal). The more liberal distribution of preverbal objects would itself be the result of the increased positional flexibility of preverbal subjects. The obvious advantage of this approach is that it readily provides us with an analysis of why the rate of object shift increases over time, a fact that remains otherwise unexplained. We can also speculate that in Late Latin object shift was information-structurally less marked than in Classical Latin, but needless to say, further research is needed to check whether this is correct.

This being said, we can now move on to apply the system from Yang $(2000,2002)$ to the Latin corpus data.

\footnotetext{
${ }^{28}$ I wish to remain agnostic as to whether the pragmatic correlates of object shift (say its conditions of usage) change over time or rather remain stable.
} 


\subsection{Periodization}

Recall that my initial hypothesis concerning the existence of Grammar A and Grammar B was based on the data summarized in Graph 2, which show that at around 200 AD (or perhaps a bit earlier), the headedness of the verb phrase $(v \mathrm{P})$ ceases to be independent from the headedness of TP, witness the rather sudden decrease in productivity of the order VOAux. This observation, as well as the data on the distribution of internal arguments discussed in section 3.3, prompted me to the conclusion that Grammar A is more frequently used in the period from $200 \mathrm{BC}$ until $200 \mathrm{AD}$, and that Grammar $\mathrm{B}$ is the dominant one in the following four centuries.

Recall also that in many cases it is impossible to tell whether a given clause was generated by Grammar A or by Grammar B, as both can produce VPAux and AuxVP-orders alike. What I will do to deal with this problem is make a simple binary distinction between the earlier and the later period in my corpus (first four centuries vs. last four centuries), and assume that in the former we see Grammar A at work, and in the latter Grammar B. The sharp contrast observed in Graph 2 (which I interpret to mean that somewhere before 200 AD the frequency of usage of Grammar B rises sharply) suggests that this idealization is not too far off the mark, but it should be obvious that it is at least to some extent a simplification of the actual situation, as there can be no doubt that some of the clauses in the earlier period are the output of Grammar B, and some in the later period of Grammar A. In any event, as I will now proceed to show, even given this approximation, a fairly clear contrast between the two periods emerges, which might help us to understand why the OV grammar eventually lost out.

\subsection{The results}

The below results are based on the analysis of a sample of 6309 clauses drawn from the corpus mentioned at the beginning of section 2.1, which all contain an auxiliary (BE or a modal), a transitive lexical verb and a non-discontinuous direct object. 2158 clauses also feature an overt, non-discontinuous subject (which can be nominal, pronominal or clausal (free relative)). The sample for the early period is slightly bigger than the one for the later period (3911 vs. 2398 clauses).

In order to calculate how fit the OV and the VO grammar are in terms of Yang's variational acquisition model, we have to look at the proportion of unambiguous OV and VOclauses in our sample. The results are summarized in Table 5 (absolute frequencies):

Table 5: Frequency of ambiguous and unambiguous OV and VO patterns.

\begin{tabular}{|c|c|c|c|c|c|c|}
\hline & \multicolumn{3}{|c|}{$\begin{array}{c}\text { Early period (200 BC - } \\
200 \text { AD, Grammar A) }\end{array}$} & \multicolumn{3}{|c|}{$\begin{array}{c}\text { Late period }(201-600 \mathrm{AD}, \\
\text { Grammar B) }\end{array}$} \\
\hline & Environment & $\mathrm{N}$ & Total & Environment & $\mathrm{N}$ & Total \\
\hline \multirow[t]{2}{*}{ Unambiguous OV } & AuxSOV & 65 & \multirow{2}{*}{487} & AuxSOV & 23 & \multirow{2}{*}{$\begin{array}{c}23 \\
(71)\end{array}$} \\
\hline & CSOVAux & 422 & & (CSOVAux) & (48) & \\
\hline \multirow[t]{2}{*}{ Unambiguous VO } & AuxVOXP & 16 & \multirow{2}{*}{420} & AuxVOXP & 30 & \multirow{2}{*}{$\begin{array}{l}30 \\
(96)\end{array}$} \\
\hline & VOAux & 404 & & (VOAux) & $(66)$ & \\
\hline Ambiguous & \multicolumn{3}{|c|}{3004} & \multicolumn{3}{|c|}{$2279(2183)$} \\
\hline Total \# of clauses & \multicolumn{3}{|c|}{3911} & \multicolumn{3}{|c|}{2332} \\
\hline
\end{tabular}


Let us have a closer look at these results. First, observe that for the sake of completeness, in the rightmost column I added how frequently the two patterns that only in a Grammar A setting constitute unambiguous evidence for either the OV or the VO grammar are attested. However, note that these two types of clauses do not quite have the same status: as we have seen, the CSOVAux pattern becomes ambiguous, but VOAux-orders in principle still provide unambiguous evidence for the VO grammar, even in times when the grammar that is needed to generate them (Grammar A) was on its way out. Below, I will not take into account the evidence from Late Latin VOAux-clauses when calculating the fitness of the VO grammar in the context of Grammar B. It is important to bear in mind that this follows from my decision to treat all tokens from the early period as Grammar A clauses, and all tokens from the later period as the output of Grammar B. As mentioned, from a practical point of view assuming this type of idealization seems the only feasible option, but it is of course a simplification. In any event, the fact that I leave aside all Late Latin VOAux-clauses implies that my estimate of the fitness of the VO grammar in this period is probably overly conservative.

Second, it is very striking that the proportion of unambiguous OV and VO-clauses is much higher in Grammar A than in Grammar B. Note that this is not just a result of the fact that the these two grammars are cued in fewer environments in Grammar B: even if CSOVAux and VOAux-clauses were to be taken into account, the total of unambiguous OV and VO-clauses would still be relatively low (as compared to the figures obtained for the first four centuries).

Let us then look at the estimated fitness of the OV and the VO grammar in both periods. The results are summarized in Table 6:

Table 6: Fitness of the OV and VO grammar over time.

\begin{tabular}{|l|c|c|}
\cline { 2 - 3 } \multicolumn{1}{c|}{} & $\begin{array}{c}\text { Early period (200 BC }- \\
\text { 200 AD, Grammar A) }\end{array}$ & $\begin{array}{c}\text { Late period (201 - 600 } \\
\text { AD, Grammar B) }\end{array}$ \\
\hline OV grammar & $487 / 3004=.162$ & $23 / 2279=.010$ \\
\hline VO grammar & $420 / 3004=.140$ & $30 / 2279=.013$ \\
\hline
\end{tabular}

Overall, the variational acquisition model seems to perform very well. On the one hand, it correctly captures the fact that in the earlier centuries the OV grammar is clearly the predominant one, with an estimated advantage over the VO grammar of $2.2 \% .{ }^{29}$ On the other hand, in the later period it gives a narrow advantage of the VO grammar over its competitor, despite the fact that in absolute terms, the fitness of the VO grammar (as well as of the OV grammar) decreases quite dramatically. This result is not only compatible with the observation that in the Late Latin period we do not witness any strong increase of the VOorder, but also with the fact that the VO grammar eventually turned out to be extremely successful, an observation that has for a long time resisted a satisfactory explanation. However, it needs to be added that in the late period the difference between the two grammars is very small, and indeed not statistically significant at the .05 level (i.e. we cannot exclude that the fact that we observe $30 \mathrm{VO}$ tokens out of a total of 53 unambiguous clauses is not due to chance, Pearson's chi-squared test, $p=0.0692$ ). This state of affairs might very well be related to the fact that the sample of unambiguous clauses is very small (only 53 for a period of 400 years). In any event, we can hope that a follow-up study that looks at a larger corpus of

\footnotetext{
${ }^{29}$ The probability of obtaining 487 OV-clauses out of a total of 907 unambiguous tokens is statistically significant (Pearson's chi-squared test, $p=.0022$ ).
} 
Late Latin might provide us with more conclusive evidence that the VO grammar was indeed fitter in a Grammar B context than its competitor.

\section{Conclusion}

In this paper I have offered a first attempt to analyse the loss of OV word orders in Latin/Romance. Assuming Yang's (2000, 2002) variational acquisition model of language change, I have suggested that the eventual decline of the OV grammar can be traced back to an independent change in the grammar of Latin, namely one concerning the way in which the clausal EPP requirement is satisfied (Danckaert 2017). The crucial Late Latin innovation was argued to be the development of optional A-movement for subjects: as an indirect result of this, in the Late Latin period the VO grammar is more robustly cued than the OV grammar, despite the fact that the overall frequency of the order VO remains more or less constant over time (and in certain environments even decreases). Given this result, Yang's model correctly predicts the VO-order to oust the competing OV pattern. I have also shown that the rate of object extraposition (which yields linear VO-sequences) remains fairly stable during the lifespan of the Latin language, which suggests that this phenomenon is unrelated to the spread of the VO-order. Finally, the rate of object shift (i.e. a non-local type of OV) can in fact be shown to increase over time. This development too was suggested to be related to the new setting of the EPP parameter and the novel patterns of subject placement that follow from it.

\section{References}

Alexiadou, Artemis \& Elena Anagnostopoulou. 1998. Parametrizing AGR: Word order, movement and EPP-checking. Natural Language and Linguistic Theory 16. 491-539.

Biberauer, Theresa. 2003. Verb second (V2) in Afrikaans: A minimalist investigation of word order variation. Cambridge: University of Cambridge dissertation.

Biberauer, Theresa \& Ian Roberts. 2005. Changing EPP parameters in the history of English: Accounting for variation and change. English Language and Linguistics 9. 5-46.

Biberauer, Theresa, Anders Holmberg \& Ian Roberts. 2014. A syntactic universal and its consequences. Linguistic Inquiry 45. 169-225.

Cardinaletti, Anna. 2004. Towards a cartography of subject positions. In Luigi Rizzi (ed.), The Structure of CP and IP, 115-165. Oxford: Oxford University Press.

Danckaert, Lieven. 2011. On the left periphery of Latin embedded clauses. Gent: Ghent University dissertation.

Danckaert, Lieven. 2012. Latin embedded clauses: The left periphery. Amsterdam: John Benjamins.

Danckaert, Lieven. 2014. The derivation of Classical Latin Aux-final clauses: Implications for the internal structure of the verb phrase. In Karen Lahousse \& Stefania Marzo (eds.), Romance languages and linguistic theory 2012, 141-159. Amsterdam: John Benjamins.

Danckaert, Lieven. 2016. Variation and change in Latin BE-periphrases: Empirical and methodological considerations. In James N. Adams \& Nigel Vincent (eds.), Early and Late Latin: Continuity or change?, 132-162. Cambridge: Cambridge University Press.

Danckaert, Lieven. 2017. The development of Latin clause structure: A study of the extended verb phrase. Oxford: Oxford University Press.

Devine, Andrew \& Laurence Stephens. 2006. Latin word order: Structured meaning and information. Oxford: Oxford University Press.

de Vries, Mark. 1999. Extraposition of relative clauses as specifying coordination. In Tina Cambier-Langeveld, Anikó Lipták, Michael Redford \& Eric Jan van der Torre (eds.), 
Proceedings of ConSole VII, 293-309. Leiden: Student Organisation of Linguistics in Europe.

Embick, David. 2000. Features, syntax and categories in the Latin perfect. Linguistic Inquiry 31. 185-230.

Fox, Danny \& Jon Nissenbaum. 1999. Extraposition and scope: A case for overt QR. In Sonya Bird, Andrew Carnie, Jason D. Haugen, and Peter Norquest, Proceedings of the 18th West Coast Conference on Formal Linguistics, 132-144. Somerville, MA: Cascadilla Press.

Guéron, Jacqueline. 1980. On the syntax and semantics of PP extraposition. Linguistic Inquiry 11.637-678.

Guéron, Jacqueline \& Robert May. 1984. Extraposition and logical form. Linguistic Inquiry 15. $1-31$.

Haegeman, Liliane. 1993a. Some speculations on argument shift, clitics and crossing in West Flemish. In Werner Abraham \& Josef Bayer (eds.), Dialektsyntax, 131-160. Opladen: Westdeutscher Verlag.

Haegeman, Liliane. 1993b. The morphology and distribution of object clitics in West Flemish. Studia Linguistica 47. 57-94.

Haegeman, Liliane. 2000. Remnant movement and OV order. In Peter Svenonius (ed.), The derivation of $O V$ and $V O, 69-96$. Amsterdam: John Benjamins.

Haegeman, Liliane, Ángel Jiménez-Fernández \& Andrew Radford. 2014. Deconstructing the Subject Condition in terms of cumulative constraint violation. The Linguistic Review 31. 73-150.

Heycock, Caroline \& Joel Wallenberg. 2013. How variational acquisition drives syntactic change: The loss of verb movement in Scandinavian. Journal of Comparative Germanic Linguistics 16. 127-157.

Huddleston, Rodney \& Geoffrey Pullum. 2002. The Cambridge grammar of the English language. Cambridge: Cambridge University Press.

Kampers-Manhe, Brigitte, Jean-Marie Marandin, Frank Drijkoningen, Jenny Doetjes \& Aafke Hulk. 2004. Subject NP inversion. In Francis Corblin \& Henriëtte de Swart (eds.), Handbook of French semantics, 553-579. Stanford, CA: Center for the Study of Language and Information.

Kayne, Richard. 1994. The antisymmetry of syntax. Cambridge, MA: The MIT Press.

Keller, Frank. 1995. Towards an account of extraposition in HPSG. In Steven Abney \& Erhard Hinrichs (eds.), Proceedings of the seventh conference of the European chapter of the Association for Computational Linguistics, 301-306. Dublin: Association for Computational Linguistics.

Kroch, Anthony. 1989. Reflexes of grammar in patterns of language change. Language Variation and Change 1. 199-244.

Kroch, Anthony. 1994. Morphosyntactic variation. In Beals Katherine, Jeannette Denton, Robert Knippen, Lynette Melnar, Hisami Suzuki \& Erica Zeinfeld (eds.), Papers from the thirtieth regional meeting of the Chicago Linguistics Society, volume 2: The Parasession on variation in linguistic theory, 180-201. Chicago: Chicago Linguistics Society.

Lightfoot, David. 1979. Principles of diachronic syntax. Cambridge: Cambridge University Press.

Mackenzie, Ian \& Wim van der Wurff. 2012. Relic syntax in Middle English and Medieval Spanish: parameter interaction in language change. Language 88. 846-876.

Pintzuk, Susan. 1999. Phrase structures in competition: Variation and change in Old English word order. New York: Garland.

Pintzuk, Susan. 2003. Variationist approaches to syntactic change. In Brian D. Joseph \& 
Richard D. Janda (eds.), The handbook of historical linguistics, 509-528. Oxford: Blackwell.

Pintzuk, Susan \& Anthony Kroch. 1989. The rightward movement of complements and adjuncts in the Old English of Beowulf. Language Variation and Change 1. 115-143.

Ott, Dennis \& Mark de Vries. 2016. Right-dislocation as deletion. Natural Language and Linguistic Theory 34. 641-690.

Rizzi, Luigi. 2006. On the form of chains: Criterial positions and ECP effects. In Lisa Cheng, \& Norbert Corver (eds.), Wh-movement: Moving on, 97-133. Cambridge, MA: The MIT Press.

Santorini, Beatrice. 1993. The rate of phrase structure change in the history of Yiddish. Language Variation and Change 5. 257-283.

Sheehan, Michelle. 2010. Extraposition and antisymmetry. Linguistic Variation Yearbook 10. 203-254.

Svenonius, Peter. 1992. Movement of $\mathrm{P}^{\circ}$ in the English verb-particle construction. In $\mathrm{H}$. Andrew Black \& James McCloskey (eds.), Syntax at Santa Cruz 1, 93-113. Santa Cruz, CA: Syntax Research Center of the University of California at Santa Cruz.

Yang, Charles. 2000. Internal and external forces in language change. Language Variation and Change 12. 231-250.

Yang, Charles. 2002. Knowledge and learning in natural language. Oxford: Oxford University Press.

Wallenberg, Joel. 2015. Antisymmetry and Heavy NP Shift across Germanic. In Theresa Biberauer \& George Walkden (eds.), Syntax over time: Lexical, morphological and information-structural interactions, 336-349. Oxford: Oxford University Press. 